\title{
Rational and Near-Rational Bubbles Without Drift*
}

\author{
Kevin J. Lansing ${ }^{\dagger}$ \\ Federal Reserve Bank of San Francisco
}

May 20, 2007

\begin{abstract}
This paper derives a general class of intrinsic rational bubble solutions in a standard Lucas-type asset pricing model. I show that the rational bubble component of the pricedividend ratio can evolve as a geometric random walk without drift. The volatility of bubble innovations depends exclusively on fundamentals. Starting from an arbitrarily small positive value, the rational bubble expands and contracts over time in an irregular, wholly endogenous fashion, always returning to the vicinity of the fundamental solution. I also examine a near-rational solution in which the representative agent does not construct separate forecasts for the fundamental and bubble components of the asset price. Rather, the agent constructs only a single forecast for the total asset price that is based on a geometric random walk without drift. The agent's forecast rule is parameterized to match the moments of observable data. In equilibrium, the actual law of motion for the price-dividend ratio is stationary, highly persistent, and nonlinear. The agent's forecast errors exhibit near-zero autocorrelation at all lags, making it difficult for the agent to detect a misspecification of the forecast rule. Unlike a rational bubble, the near-rational solution allows the asset price to occasionally dip below its fundamental value. Under mild risk aversion, the near-rational solution generates pronounced low-frequency swings in the price-dividend ratio, positive skewness, excess kurtosis, and time-varying volatility - all of which are present in long-run U.S. stock market data. An independent contribution of the paper is to demonstrate an approximate analytical solution for the fundamental asset price that employs a nonlinear change of variables.
\end{abstract}

Keywords: Asset Pricing, Rational Bubbles, Excess Volatility, Learning.

JEL Classification: E44, G12.

\footnotetext{
${ }^{*}$ For helpful comments and suggestions, I thank participants at the 2007 Meeting of the Society for Nonlinear Dynamics and Econometrics.

$\dagger$ Research Department, Federal Reserve Bank of San Francisco, P.O. Box 7702, San Francisco, CA 94120-7702, (415) 974-2393, FAX: (415) 977-4031, email: kevin.j.lansing@sf.frb.org, homepage: www.frbsf.org/economics/economists/klansing.html
} 


\section{Introduction}

\subsection{Overview}

Rational bubbles offer a potential explanation for excess volatility of stock prices and sustained run-ups above fundamental values. Unfortunately, the typical rational bubble solution requires the equilibrium price-dividend ratio to increase without bound, which is not a realistic model for long-run stock market behavior. Hall (2001, p. 3) dismisses the idea that "intelligent people [would] believe that the value of a stock will become larger and larger in relation to all other quantities in the economy." An alternative setup assumes that the rational bubble periodically collapses according to some known probability function, but the probability function is an element that is determined completely outside of the model. ${ }^{1}$

This paper derives a general class of intrinsic rational bubble solutions that address the above criticisms. The framework for the analysis is a standard Lucas (1978) type asset pricing model. For any given value of risk aversion, I show that there are two distinct rational bubble solutions for which the bubble component of the price-dividend ratio evolves as a geometric random walk without drift, i.e., the unconditional mean of the bubble growth rate is zero. Under each solution, the volatility of bubble innovations depends exclusively on fundamentals. Starting from an arbitrarily small positive value, the rational bubble expands and contracts over time in a irregular, wholly endogenous fashion. Although the price-dividend ratio is nonstationary, the trajectory always returns to the vicinity of the fundamental asset price. I show that driftless rational bubbles are part of a continuum of equilibrium solutions that involve an explicit trade-off between the mean and volatility of the bubble drift rate. The positive drift solution derived by Froot and Obstfeld (1991) can be recovered as a special case along this continuum.

All rational bubble solutions require the representative agent to construct separate forecasts for the fundamental and bubble components of the asset price. An agent with limited computational resources may be inclined to construct only a single forecast that predicts the movement of the total asset price (fundamental plus bubble). Adopting this setup, I solve for a near-rational, "restricted perceptions equilibrium" in which the agent's perceived law of motion for the price-dividend ratio is a geometric random walk without drift. The agent's forecast rule is similar in form to the corresponding rational forecast, but involves fewer parameters. The parameters of the agent's forecast rule are chosen to match the moments of observable data. $^{2}$

In equilibrium, the actual law of motion for the price-dividend ratio is stationary, highly persistent, and nonlinear. The agent's forecast errors exhibit near-zero autocorrelation at all lags, making it difficult for the agent to detect a misspecification of the forecast rule. Unlike a rational bubble, the near-rational solution allows the asset price to occasionally dip below its fundamental value. Under mild risk aversion, the near-rational solution generates pronounced

\footnotetext{
${ }^{1}$ For examples, see Blanchard (1979), Blanchard and Watson (1982), Evans (1991), Fukata (1998), and Van Norden and Schaller (1999), among others.

${ }^{2}$ The restricted perceptions equilibrium concept is described in Evans and Honkapohja (2001, Chapter 13).
} 
low-frequency swings in the price-dividend ratio, positive skewness, excess kurtosis, and timevarying volatility - all of which are present in long-run U.S. stock market data.

An independent contribution of the paper is to demonstrate an approximate analytical solution for the fundamental asset price. The solution employs a change of variables that captures more of the model's nonlinearity relative to the change of variables employed by Calin, et. al (2005). The behavior of the changed variable is well-captured by a simple exponential function, as opposed to the high-order polynomial function employed by Calin, et. al (2005). I show that the approximate solution yields results that are very close to the exact theoretical solution derived by Burnside (1998) for the case of autocorrelated dividend growth.

\subsection{Related Literature}

Numerous empirical studies starting with Shiller (1981) and LeRoy and Porter (1981) have demonstrated that stock prices exhibit "excess volatility," i.e., observed prices are much more variable than the discounted stream of ex post realized dividends. The finding of excess volatility is robust to a variety of discounting methods, as discussed by Shiller (2003). LeRoy (2004, p.784) argues that "bubbles are a viable candidate for an explanation for the volatility of asset prices, even if it is not entirely clear how bubbles should be modeled." Evidence of bubbles can be found throughout history in various countries and asset markets, as detailed in Hunter, Kaufman, and Pomerleano (2003). Gürkaynak (2007) reviews the vast literature on econometric tests for the presence of asset price bubbles. Research that seeks to explain stock market behavior using some type of distorted belief or misspecified forecast rule in a representative agent framework includes Barsky and Delong (1993), Timmerman (1996), Barberis, Schleifer, and Vishney (1998), Cecchetti, Lam, and Mark (2000), Abel (2002), Lansing (2006), and Branch and Evans (2006), among others. Models of asset price bubbles that involve rational and non-rational agents in the same economy include Delong et al. (1990), Brock and Hommes (1998), Abreu and Brunnermeier (2003), and Scheinkman and Wong (2003).

\section{The Model}

Equity shares are priced using the frictionless pure exchange model of Lucas (1978). There is a representative agent who can purchase shares to transfer wealth from one period to another. Each share pays an exogenous stream of stochastic dividends in perpetuity.

The agent's problem is to maximize

$$
E_{0} \sum_{t=0}^{\infty} \beta^{t}\left[\frac{c_{t}^{1-\alpha}-1}{1-\alpha}\right],
$$

subject to the budget constraint

$$
c_{t}+p_{t} s_{t}=\left(p_{t}+d_{t}\right) s_{t-1},
$$


where $c_{t}$ is the agent's consumption in period $t, \beta$ is the subjective time discount factor, and $\alpha$ is the coefficient of relative risk aversion (the inverse of the intertemporal elasticity of substitution). When $\alpha=1$, the within-period utility function can be written as $\log \left(c_{t}\right)$. The symbol $E_{t}$ represents the mathematical expectation operator evaluated using the objective distribution of dividend growth (which is presumed known to the agent). The symbol $p_{t}$ denotes the ex-dividend price of the equity share, $d_{t}$ is the dividend, and $s_{t}$ is the number of shares purchased in period $t$.

The growth rate of dividends $x_{t} \equiv \log \left(d_{t} / d_{t-1}\right)$ is governed by the following stochastic process

$$
x_{t}=\bar{x}+\rho\left(x_{t-1}-\bar{x}\right)+\varepsilon_{t}, \quad \varepsilon_{t} \sim N\left(0, \sigma_{\varepsilon}^{2}\right),
$$

where $|\rho|<1$. The mean growth rate is $\bar{x}$ and the variance is given by $\sigma_{\varepsilon}^{2} /\left(1-\rho^{2}\right)$.

The first-order condition that governs the agent's share holdings is given by

$$
p_{t}=E_{t}\left[\beta\left(\frac{c_{t+1}}{c_{t}}\right)^{-\alpha}\left(p_{t+1}+d_{t+1}\right)\right] .
$$

Equation (4) can be rearranged to obtain

$$
1=E_{t}\left[M_{t+1} R_{t+1}\right]
$$

where $M_{t+1}=\beta\left(c_{t+1} / c_{t}\right)^{-\alpha}$ is the stochastic discount factor and $R_{t+1}=\left(p_{t+1}+d_{t+1}\right) / p_{t}$ is the gross return from holding the equity share from period $t$ to $t+1$. Defining the price-dividend ratio as $y_{t} \equiv p_{t} / d_{t}$, the gross equity return can be written as

$$
R_{t+1}=\left(\frac{y_{t+1}+1}{y_{t}}\right) \exp \left(x_{t+1}\right) .
$$

Without loss of generality, shares are assumed to exist in unit net supply. Market clearing therefore implies $s_{t}=1$ for all $t$. Substituting this equilibrium condition into the budget constraint (2) yields, $c_{t}=d_{t}$ for all $t$. In equilibrium, equation (4) can now be written as

$$
y_{t}=E_{t}\left[\beta \exp \left(\theta x_{t+1}\right)\left(y_{t+1}+1\right)\right] \text {, }
$$

where $\theta \equiv 1-\alpha$. Equation (7) shows that the price-dividend ratio in period $t$ depends on the agent's subjective joint forecast of next period's dividend growth rate $x_{t+1}$ and next period's price-dividend ratio $y_{t+1}$. It is convenient to transform equation (7) using a nonlinear change of variables to obtain

$$
z_{t}=\beta \exp \left(\theta x_{t}\right)\left[E_{t} z_{t+1}+1\right],
$$

where $z_{t} \equiv \beta \exp \left(\theta x_{t}\right)\left(y_{t}+1\right)$. Under this formulation, $z_{t}$ represents a composite variable that depends on both the growth rate of dividends and the price-dividend ratio. Equation (8) shows that the value of $z_{t}$ in period $t$ depends on the agent's conditional forecast of that same variable. By making use of the definition of $z_{t}$, equation (7) can be written as $y_{t}=E_{t} z_{t+1}$. Hence, the equilibrium price-dividend ratio is the conditional forecast of $z_{t+1}$. 


\section{Fundamental Solution}

The fundamental value of the share price is uniquely pinned down by the agent's rational forecast of the discounted stream of future dividends. Equation (8) can be iterated forward to substitute out $z_{t+1+k}$ for $k=0,1,2, \ldots$ Applying the law of iterated expectations and imposing a transversality condition yields the following present-value pricing equation

$$
\begin{aligned}
z_{t}^{\mathrm{f}}= & \beta \exp \left(\theta x_{t}\right) E_{t}\left\{1+\beta \exp \left(\theta x_{t+1}\right)+\beta^{2} \exp \left(\theta x_{t+1}+\theta x_{t+2}\right)+\right. \\
& \left.\beta^{3} \exp \left(\theta x_{t+1}+\theta x_{t+2}+\theta x_{t+3}\right) \ldots\right\},
\end{aligned}
$$

where $z_{t}^{\mathrm{f}}$ represents the fundamental value of the forecast variable. Following Burnside (1998), the expectation of the infinite sum in (9) can be explicitly evaluated to yield the following exact analytical solution

$$
\begin{aligned}
z_{t}^{\mathrm{f}} & =\beta \exp \left(\theta x_{t}\right)\left\{1+\sum_{i=1}^{\infty} \beta^{i} \exp \left[\kappa_{i}+\gamma_{i}\left(x_{t}-\bar{x}\right)\right]\right\}, \\
\kappa_{i} & =\theta \bar{x} i+\frac{\theta^{2} \sigma_{\varepsilon}^{2}}{2\left(1-\rho^{2}\right)}\left[i-\frac{2 \rho\left(1-\rho^{i}\right)}{1-\rho}+\frac{\rho^{2}\left(1-\rho^{2 i}\right)}{1-\rho^{2}}\right], \\
\gamma_{i} & =\frac{\theta \rho\left(1-\rho^{i}\right)}{1-\rho} .
\end{aligned}
$$

Given $z_{t}^{\mathrm{f}}$, we can recover the fundamental price-dividend ratio by applying the definitional relationship $y_{t}^{\mathrm{f}}=\beta^{-1} \exp \left(-\theta x_{t}\right) z_{t}^{\mathrm{f}}-1$. This procedure yields the result that $y_{t}^{\mathrm{f}}$ is equal to the infinite sum inside the curly brackets in equation (10). In the special case when $\rho=0$, we have $\gamma_{i}=0$ such that $y_{t}^{\mathrm{f}}$ is constant. ${ }^{3}$

During model simulations, computation of a truncated version of the infinite sum in equation (10) for each realization of $x_{t}$ can be quite time consuming. Moreover, equation (10) does not lend itself to analytical moment calculations for the asset pricing variables of interest. To avoid these drawbacks, the following proposition presents an approximate analytical solution for $z_{t}^{\mathrm{f}}$.

Proposition 1. An approximate analytical solution for the fundamental value of the forecast variable is given by

$$
z_{t}^{\mathrm{f}}=\exp \left[a_{0}+a_{1}\left(x_{t}-\bar{x}\right)\right]
$$

where $a_{1}$ solves the following nonlinear equation

$$
a_{1}=\frac{\theta}{1-\rho \beta \exp \left[\theta \bar{x}+\frac{1}{2}\left(a_{1}\right)^{2} \sigma_{\varepsilon}^{2}\right]},
$$

\footnotetext{
${ }^{3}$ Throughout the paper, I use Greek letters such as $\kappa, \gamma$, and $\lambda$, to represent constants implied by exact analytical solutions and English letters such as $a, b, k$, and $m$ to represent constants implied by approximate analytical solutions.
} 
and $a_{0}$ is given by

$$
a_{0}=\log \left\{\frac{\beta \exp (\theta \bar{x})}{1-\beta \exp \left[\theta \bar{x}+\frac{1}{2}\left(a_{1}\right)^{2} \sigma_{\varepsilon}^{2}\right]}\right\}
$$

provided that $\beta \exp \left[\theta \bar{x}+\frac{1}{2}\left(a_{1}\right)^{2} \sigma_{\varepsilon}^{2}\right]<1$.

Proof: See appendix.

Two values of $a_{1}$ satisfy the nonlinear equation. The inequality restriction selects the value of $a_{1}$ with lower magnitude to ensure that the non-stochastic steady-state level of $z_{t}^{\mathrm{f}}$ is positive, as given by $\exp \left(a_{0}\right)$. The approximate solution in Proposition 1 is much simpler in structure than the one derived by Calin, et. al (2005) for their corresponding model with no habit formation. These authors numerically approximate the law of motion of the changed variable $q_{t}^{\mathrm{f}} \equiv \exp \left(-\rho \theta x_{t}\right) y_{t}^{\mathrm{f}}$ using a polynomial of the form

$$
\underbrace{\left(\frac{d_{t}}{d_{t-1}}\right)^{-\rho(1-\alpha)}\left(\frac{p_{t}^{\mathrm{f}}}{d_{t}}\right)}_{q_{t}^{\mathrm{f}}}=\widehat{a}_{0}+\sum_{i=1}^{8} \widehat{a}_{i}\left(x_{t}-\bar{x}\right)^{i},
$$

which involves a total of nine Taylor-series coefficients. ${ }^{4}$ In contrast, Proposition 1 , analytically approximates the law of motion of the changed variable $z_{t}^{\mathrm{f}} \equiv \beta \exp \left(\theta x_{t}\right)\left(y_{t}^{\mathrm{f}}+1\right)$ using the exponential form

$$
\underbrace{\beta\left(\frac{d_{t}}{d_{t-1}}\right)^{1-\alpha}\left(\frac{p_{t}^{\mathrm{f}}}{d_{t}}+1\right)}_{z_{t}^{\mathrm{f}}}=\exp \left[a_{0}+a_{1}\left(x_{t}-\bar{x}\right)\right],
$$

which involves only two Taylor-series coefficients, $a_{0}$ and $a_{1}$. The change of variables that defines $z_{t}^{\mathrm{f}}$ captures more of the model's nonlinearity relative to that employed by Calin, et. al (2005). Moreover, the approximation in Proposition 1 exploits the curvature of the exponential function rather than relying on a very high-order polynomial in $\left(x_{t}-\bar{x}\right)$ to capture curvature.

We can recover an approximate solution for the fundamental price-dividend ratio by applying the equilibrium relationship $y_{t}^{\mathrm{f}}=E_{t} z_{t+1}^{\mathrm{f}}$, yielding

$$
y_{t}^{\mathrm{f}}=E_{t} z_{t+1}^{\mathrm{f}}=\exp \left[a_{0}+a_{1} \rho\left(x_{t}-\bar{x}\right)+\frac{1}{2}\left(a_{1}\right)^{2} \sigma_{\varepsilon}^{2}\right] \text {. }
$$

Figure 1 compares the approximate and exact analytical solutions for two different calibrations of the model. Throughout the paper, the agent's discount factor is set equal to $\beta=0.96$, a typical value for annual time periods. In Figure 1a, the risk coefficient is set equal to $\alpha=2$ and the consumption growth process is calibrated to match the mean, standard deviation,

\footnotetext{
${ }^{4}$ See Calin, et. al (2005), Table 1, p. 977.
} 
1a: Fundamental Price-Dividend Ratio

$\alpha=2, \quad \rho=-0.17$
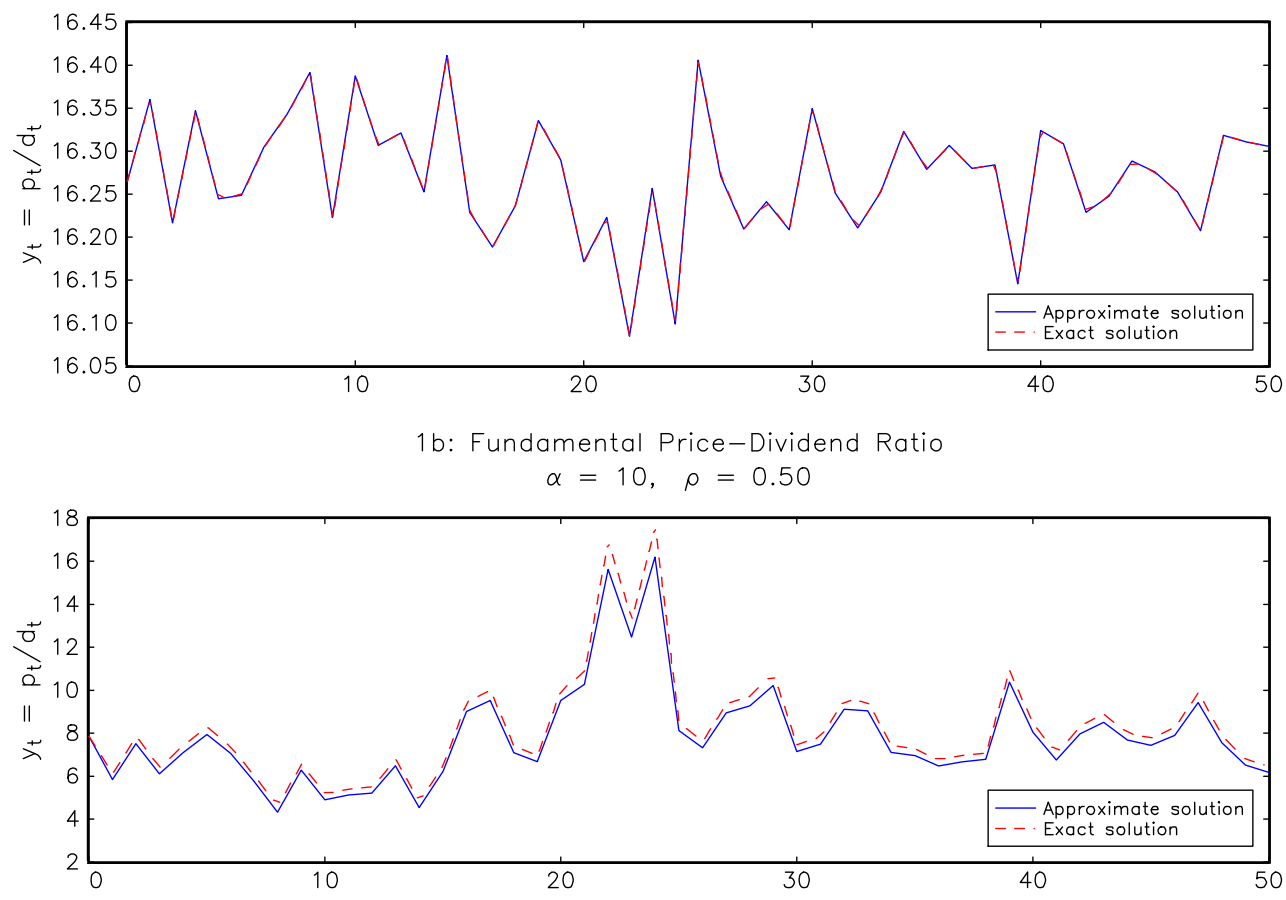

Figure 1: Approximate and exact solutions for fundamental price dividend ratio.

and autocorrelation of U.S. annual data for the growth of real per capita consumption of nondurables and services from 1890 to $2003 .{ }^{5}$ This procedure yields $\bar{x}=0.019, \sigma_{\varepsilon}=0.030$, and $\rho=-0.166$. In Figure $1 \mathrm{~b}$, the risk coefficient is increased to $\alpha=10$ while the persistence parameter for consumption growth is increased to $\rho=0.5$, with the value of $\sigma_{\varepsilon}$ adjusted downward to maintain the same volatility of consumption growth as in Figure 1a.

In Figure 1a, the approximate solution is virtually indistinguishable from the exact fundamental solution. For this calibration, the standard deviation of the price dividend ratio is only 0.07 versus 13.0 in long-run U.S. data. In Figure 1b, where the model calibration is less plausible, the approximate solution is less accurate. In this case, the root mean squared percentage error of the approximation is 4.7 percent. Collard and Juillard (2001) also find that approximation errors increase with risk aversion and the persistence of the consumption growth process. A more accurate approximation could be obtained by increasing the order of the polynomial that appears inside the exponential function on the right-side of equation (14). Experiments with the model show that a quadratic polynomial inside the exponential is successful in reducing the approximation error to nearly zero for the calibration of Figure 1b.

As shown in the appendix, the approximate fundamental solution can be used to derive

\footnotetext{
${ }^{5}$ Long-run annual data for U.S. consumption and U.S. stock market variables are from Robert Shiller's website: http://www.econ.yale.edu/ $\sim$ shiller/.
} 
the following expressions for the unconditional moments of the asset pricing variables

$$
\begin{aligned}
& E\left[\log \left(y_{t}^{\mathrm{f}}\right)\right]=a_{0}+\frac{1}{2}\left(a_{1}\right)^{2} \sigma_{\varepsilon}^{2}, \\
& \operatorname{Var}\left[\log \left(y_{t}^{\mathrm{f}}\right)\right]=\frac{\left(a_{1} \rho\right)^{2} \sigma_{\varepsilon}^{2}}{1-\rho^{2}}, \\
& E\left[\log \left(R_{t+1}^{\mathrm{f}}\right)\right]=-\log (\beta)+\alpha \bar{x}-\frac{1}{2}\left(a_{1}\right)^{2} \sigma_{\varepsilon}^{2}, \\
& \operatorname{Var}\left[\log \left(R_{t+1}^{\mathrm{f}}\right)\right]=\left[\frac{\alpha^{2}}{1-\rho^{2}}+\left(a_{1}\right)^{2}+2 \alpha a_{1}\right] \sigma_{\varepsilon}^{2} .
\end{aligned}
$$

Given equations (16) through (19), the unconditional moments of $y_{t}^{\mathrm{f}}$ and $R_{t+1}^{\mathrm{f}}$ can be computed by making use of the properties of the log-normal distribution. ${ }^{6}$

\section{Rational Bubble Solutions}

The present-value pricing equation (9) imposes a no-arbitrage condition across all future time periods whereas equation (8) imposes a no-arbitrage condition only from period $t$ to $t+1$. Since equation (8) does not enforce a transversality condition, it admits solutions where $z_{t}$ can deviate from the fundamentals-based value." These "rational bubble" solutions have been proposed as a way to account for the empirical observation that stock prices are much more volatile than the discounted stream of ex post dividends. The underlying assumption is that agents are forward-looking, but not to the extreme degree implied by the transversality condition. $^{8}$

The forecast variable $z_{t}$ that appears in equation (8) can be disaggregated as follows

$$
z_{t}=z_{t}^{\mathrm{f}}+z_{t}^{\mathrm{b}}
$$

where $z_{t}^{\mathrm{f}}$ satisfies the present-value pricing equation (9) and hence (8). The bubble component of the forecast variable is defined as $z_{t}^{\mathrm{b}} \equiv \beta \exp \left(\theta x_{t}\right) y_{t}^{\mathrm{b}}$, where $y_{t}^{\mathrm{b}}$ is the bubble component of the price-dividend ratio. Substituting equation (20) into (8) yields the following expectational difference equation that governs the evolution of the bubble component

$$
z_{t}^{\mathrm{b}}=\beta \exp \left(\theta x_{t}\right) E_{t} z_{t+1}^{\mathrm{b}} .
$$

\footnotetext{
${ }^{6}$ If a random variable $w_{t}$ is $\log$-normally distributed, then $E\left(w_{t}\right)=\exp \left\{E\left[\log \left(w_{t}\right)\right]+\frac{1}{2} \operatorname{Var}\left[\log \left(w_{t}\right)\right]\right\}$ and $\operatorname{Var}\left(w_{t}\right)=E\left(w_{t}\right)^{2}\left\{\exp \left(\operatorname{Var}\left[\log \left(w_{t}\right)\right]\right)-1\right\}$.

${ }^{7}$ Santos and Woodford (1997) derive a set of technical conditions that must be satisifed for the existence of rational bubbles in an intertemporal competitive equilibrium.

${ }^{8}$ Regarding the transversality condition and other technical arguments against rational bubbles, LeRoy (2004, p. 801), remarks 'It is a testament to economists' capacity for abstraction that they have accepted without question that an intricate theoretical argument against bubbles has somehow migrated from the pages of Econometrica to the floor of the New York Stock Exchange."
} 
Together, equations (8) and (21) imply

$$
\underbrace{E_{t} z_{t+1}}_{y_{t}}=\underbrace{E_{t} z_{t+1}^{\mathrm{f}}}_{y_{t}^{\mathrm{f}}}+\underbrace{E_{t} z_{t+1}^{\mathrm{b}}}_{y_{t}^{\mathrm{b}}},
$$

which shows that $E_{t} z_{t+1}$ is the sum of two separate forecasts that pertain to the fundamental and bubble components, respectively.

\subsection{Intrinsic Rational Bubbles With Drift}

The typical rational bubble solution requires the equity price to grow faster than dividends in perpetuity, i.e., the bubble component of price-dividend ratio exhibits positive drift. To illustrate the idea, Proposition 2 generalizes the intrinsic rational bubble solution of Froot and Obstfeld (1991) to allow for risk aversion and autocorrelated dividend growth. Froot and Obstfeld (1991) consider the special case of $\rho=0$ and $\alpha=0$ ( $\operatorname{such}$ that $\theta=1$ ). The bubble is "intrinsic" because the stochastic drift rate depends exclusively on fundamentals; there is no exogenous crash probability appended to the model.

Proposition 2. The Froot-Obstfeld intrinsic rational bubble takes the form

$$
\begin{aligned}
z_{t}^{\mathrm{b}} & =\eta\left[\frac{d_{t}^{\lambda_{1}}}{d_{t-1}^{\rho \lambda_{1}+\theta}}\right], \quad \eta>0, \\
& =z_{t-1}^{\mathrm{b}} \exp \left[\lambda_{1} x_{t}-\left(\rho \lambda_{1}+\theta\right) x_{t-1}\right], \quad z_{0}^{\mathrm{b}}>0,
\end{aligned}
$$

where $d_{t}$ is the level of dividends, $\eta$ is an arbitrary positive constant that determines $z_{0}^{\mathrm{b}}$, and $\lambda_{1}$ is a root of the quadratic equation

$$
\frac{1}{2}\left(\lambda_{1}\right)^{2} \sigma_{\varepsilon}^{2}+\lambda_{1} \bar{x}(1-\rho)+\log (\beta)=0 .
$$

Proof: See appendix.

Given $z_{t}^{\mathrm{b}}$, we can recover the bubble component of the price-dividend ratio by applying the definitional relationship $y_{t}^{\mathrm{b}}=\beta^{-1} \exp \left(-\theta x_{t}\right) z_{t}^{\mathrm{b}}$, yielding

$$
\begin{aligned}
y_{t}^{\mathrm{b}} & =\frac{\eta}{\beta}\left[\frac{d_{t}^{\lambda_{1}-\theta}}{d_{t-1}^{\rho \lambda_{1}}}\right], \\
& =y_{t-1}^{\mathrm{b}} \exp \left[\left(\lambda_{1}-\theta\right) x_{t}-\rho \lambda_{1} x_{t-1}\right], \quad y_{0}^{\mathrm{b}}>0 .
\end{aligned}
$$

From equation (23), we see that the rational bubble must be positive and must exist from the first day of trading onwards, as demonstrated originally by Diba and Grossman (1988). Defining the stochastic bubble drift rate as $\mu_{t}^{\mathrm{b}} \equiv \log \left(y_{t}^{\mathrm{b}} / y_{t-1}^{\mathrm{b}}\right)$, we have

$$
\begin{aligned}
E\left(\mu_{t}^{\mathrm{b}}\right) & =\left[\lambda_{1}(1-\rho)-\theta\right] \bar{x} \\
\operatorname{Var}\left(\mu_{t}^{\mathrm{b}}\right) & =\left[\left(\lambda_{1}-\theta\right)^{2}+\left(\rho \lambda_{1}\right)^{2}-2 \rho^{2} \lambda_{1}\left(\lambda_{1}-\theta\right)\right] \frac{\sigma_{\varepsilon}^{2}}{1-\rho^{2}} .
\end{aligned}
$$


The quadratic equation that determines the value of $\lambda_{1}$ has two roots - one positive and one negative. The positive root is associated with an expanding bubble $E\left(\mu_{t}^{\mathrm{b}}\right)>0$ while the negative root is associated with a collapsing bubble $E\left(\mu_{t}^{\mathrm{b}}\right)<0$. A collapsing bubble will become vanishingly small as $t \rightarrow \infty$, so attention is typically restricted to the positive root. ${ }^{9}$ Starting from an arbitrarily small positive value $y_{0}^{\mathrm{b}}>0$, the positive root solution predicts that price-dividend ratio $y_{t}=y_{t}^{\mathrm{f}}+y_{t}^{\mathrm{b}}$ will increase without bound, never returning to the vicinity of the fundamental value $y_{t}^{\mathrm{f}}$.

Proposition 3 presents an alternate rational bubble solution that exists only when $\rho \neq 0$.

Proposition 3. Provided that $\rho \neq 0$, there exists an intrinsic rational bubble of the form

$$
z_{t}^{\mathrm{b}}=z_{t-1}^{\mathrm{b}} \exp \left[\lambda_{0}+\lambda_{1}\left(x_{t}-\bar{x}\right)\right], \quad z_{0}^{\mathrm{b}}>0,
$$

where $\lambda_{0}$ and $\lambda_{1}$ are given by

$$
\begin{aligned}
& \lambda_{0}=-\log (\beta)-\theta \bar{x}-\frac{\theta^{2} \sigma_{\varepsilon}^{2}}{2 \rho^{2}}, \\
& \lambda_{1}=-\frac{\theta}{\rho}
\end{aligned}
$$

Proof: See appendix.

Again solving for $y_{t}^{\mathrm{b}}=\beta^{-1} \exp \left(-\theta x_{t}\right) z_{t}^{\mathrm{b}}$ and defining $\mu_{t}^{\mathrm{b}} \equiv \log \left(y_{t}^{\mathrm{b}} / y_{t-1}^{\mathrm{b}}\right)$, Proposition 3 implies

$$
\begin{aligned}
E\left(\mu_{t}^{\mathrm{b}}\right) & =-\log (\beta)-\theta \bar{x}-\frac{\theta^{2} \sigma_{\varepsilon}^{2}}{2 \rho^{2}}, \\
\operatorname{Var}\left(\mu_{t}^{\mathrm{b}}\right) & =\left[\frac{1}{1-\rho^{2}}+2 \rho\right] \frac{\theta^{2} \sigma_{\varepsilon}^{2}}{\rho^{2}} .
\end{aligned}
$$

Figure 2 plots the mean and volatility of the bubble drift rate for the foregoing bubble solutions as the risk coefficient $\alpha$ is varied. As before, $\beta=0.96$ and the consumption growth process is calibrated to match U.S. data from 1890 to 2003. As risk aversion increases, the Froot-Obstfeld expanding bubble grows faster and is more volatile. The Froot-Obstfeld collapsing bubble exhibits very high volatility for any value of $\alpha$. The high volatility (which is known to the agent) raises the value $E_{t} z_{t+1}^{\mathrm{b}}$ via Jensen's inequality, thereby allowing equation (21) to be satisfied with a negative mean drift rate. The alternate bubble solution in Proposition 3 yields $E\left(\mu_{t}^{\mathrm{b}}\right)>0$ for low levels of risk aversion, but $E\left(\mu_{t}^{\mathrm{b}}\right)<0$ for high levels of risk aversion. Volatility is zero when $\alpha=1$ (the case of logarithmic utility) but increases with risk aversion thereafter. These results illustrate the existence of a trade-off between the mean and the volatility of the bubble drift rate in order to satisfy equation (21).

\footnotetext{
${ }^{9}$ The sum and product of expanding and collapsing bubble components can also be valid solutions to equation (21). Ikeda and Shibata (1992) examine bubble solutions of this type.
} 


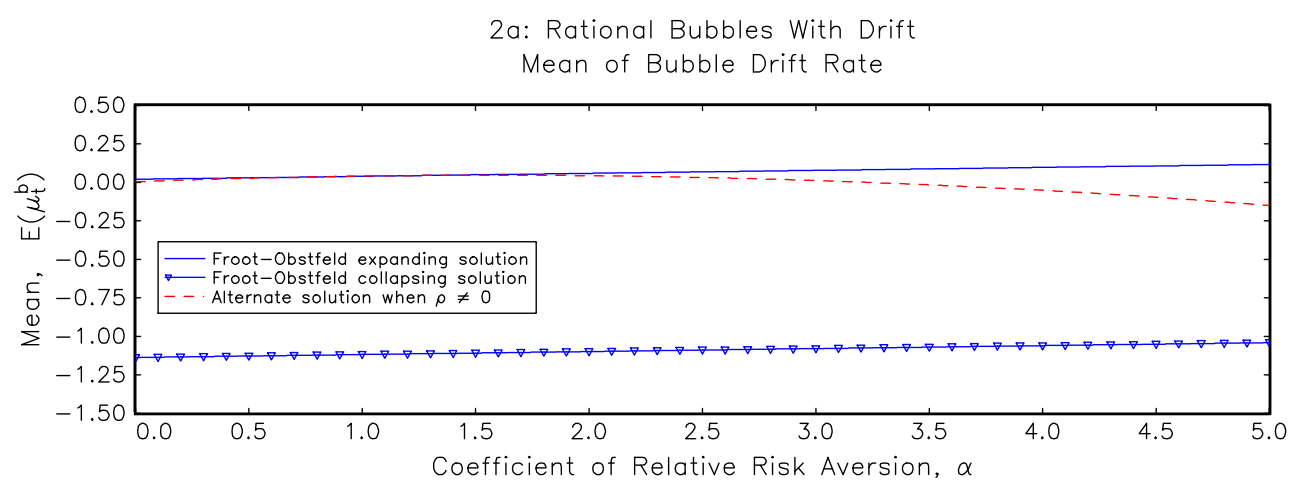

2b: Rational Bubbles With Drift Volatility of Bubble Drift Rate

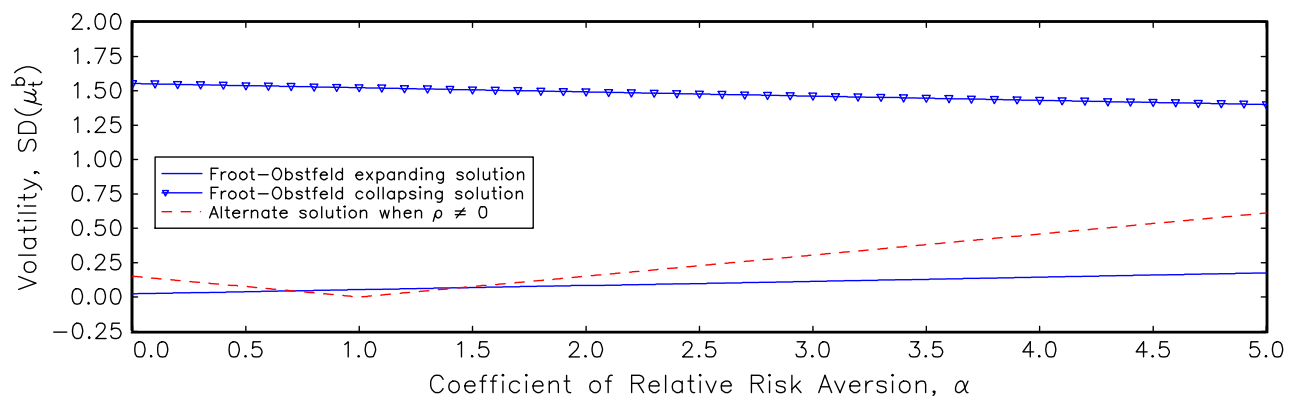

Figure 2: Mean and volatility of bubble drift rate for three different rational bubble solutions.

Figure 3 plots the U.S. price-dividend ratio from 1871 to 2003 together with an estimated exponential time trend. The estimated annual drift rate is 0.0096 (s.e. $=0.001$ ). If this trend were to continue indefinitely, as implied by a rational bubble with drift, then the U.S. ratio would double every 72 years. When $\alpha=2$, equation (24) predicts a positive drift rate of 0.059 , while equation (26) predicts a positive drift rate of 0.043 . These drift rates imply doubling times of only 12 to 16 years. Smaller predicted drift rates and longer predicted doubling times could be obtained by increasing the calibrated value of $\beta$ or, in the case of equation (26), increasing the degree of risk aversion $\alpha$. Froot and Obstfeld (1991, p. 1190) acknowledge that "It is difficult to believe that the market is literally stuck for all time on a path along which price-dividend ratios eventually explode." They argue, however, that explosive price-dividend ratios would not necessarily be observed over a finite sample period. Driffill and Sola (1998) augment the Froot-Obstfeld model to allow for regime-switching dividends. They argue that the incremental explanatory contribution of the expanding bubble component is low, relative to the regime-switching fundamentals. Their data set only extends through 1988, however, and thus does not include the dramatic, bubble-like rise in the U.S. price-dividend ratio that appears at the end of the sample in Figure 3. 


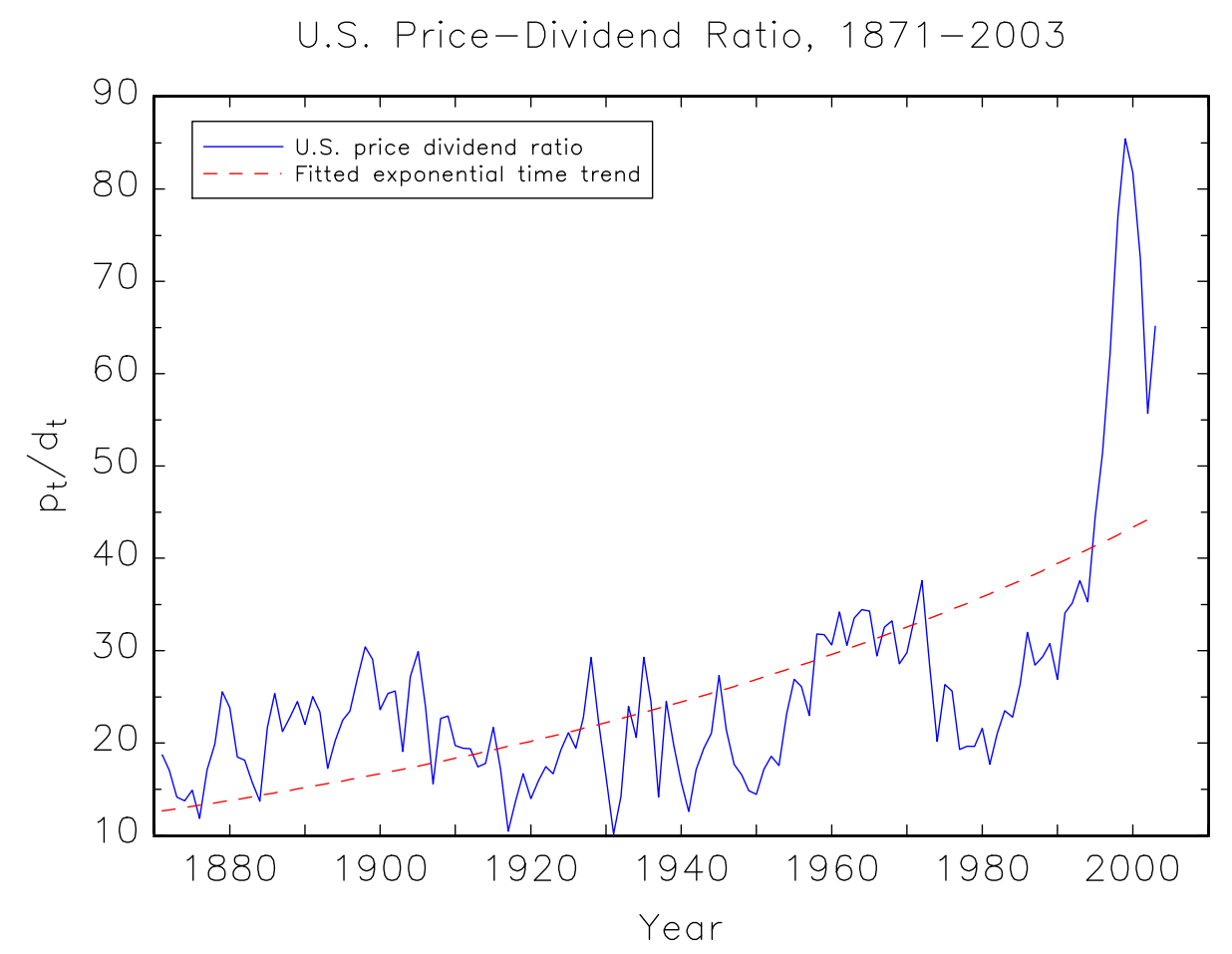

Figure 3: The annual drift rate in the U.S. price-dividend ratio is about 0.01 .

\subsection{Intrinsic Rational Bubbles Without Drift}

Proposition 4 presents a solution to equation (21) where the mean drift rate is zero by construction.

Proposition 4. An intrinsic rational bubble without drift takes the form

$$
z_{t}^{\mathrm{b}}=z_{t-1}^{\mathrm{b}} \exp \left[\lambda_{1}\left(x_{t}-\bar{x}\right)+\lambda_{2}\left(x_{t-1}-\bar{x}\right)\right], \quad z_{0}^{\mathrm{b}}>0
$$

where $\lambda_{1}$ and $\lambda_{2}$ are given by

$$
\begin{aligned}
& \lambda_{1}= \pm \sqrt{\frac{-2 \log (\beta)-2 \theta \bar{x}}{\sigma_{\varepsilon}^{2}}}, \\
& \lambda_{2}=-\left(\rho \lambda_{1}+\theta\right) .
\end{aligned}
$$

Proof: See appendix.

The results of Proposition 4 are the same, regardless of whether the agent is assumed to make use of the contemporaneous or lagged realization of $z_{t}^{\mathrm{b}}$ when forming $E_{t} z_{t+1}^{\mathrm{b}}$. Solving for $y_{t}^{\mathrm{b}}=\beta^{-1} \exp \left(-\theta x_{t}\right) z_{t}^{\mathrm{b}}$ yields the following law of motion for the bubble component of the 
4a: Rational Bubbles Without Drift

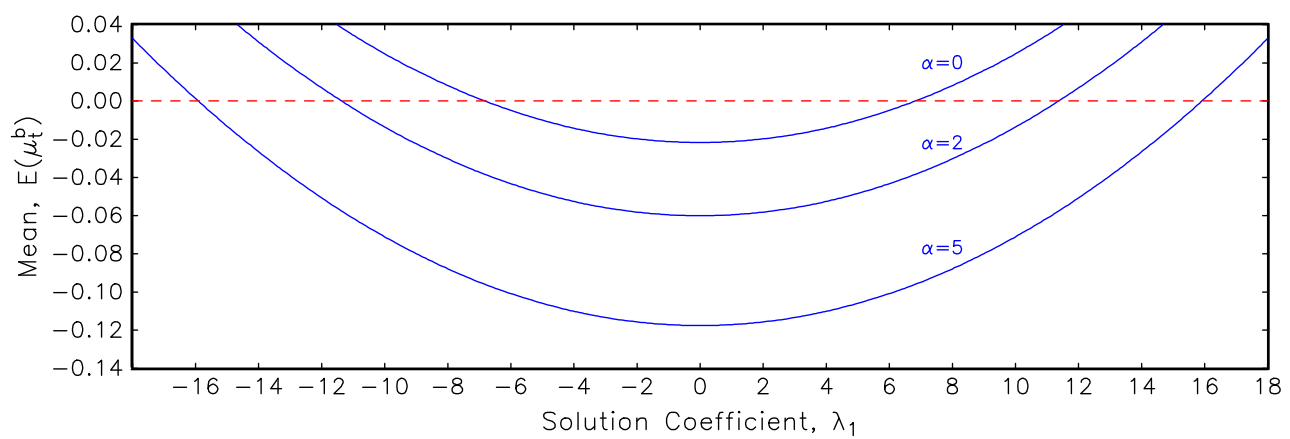

4b: Volatility of Bubble Drift Rate

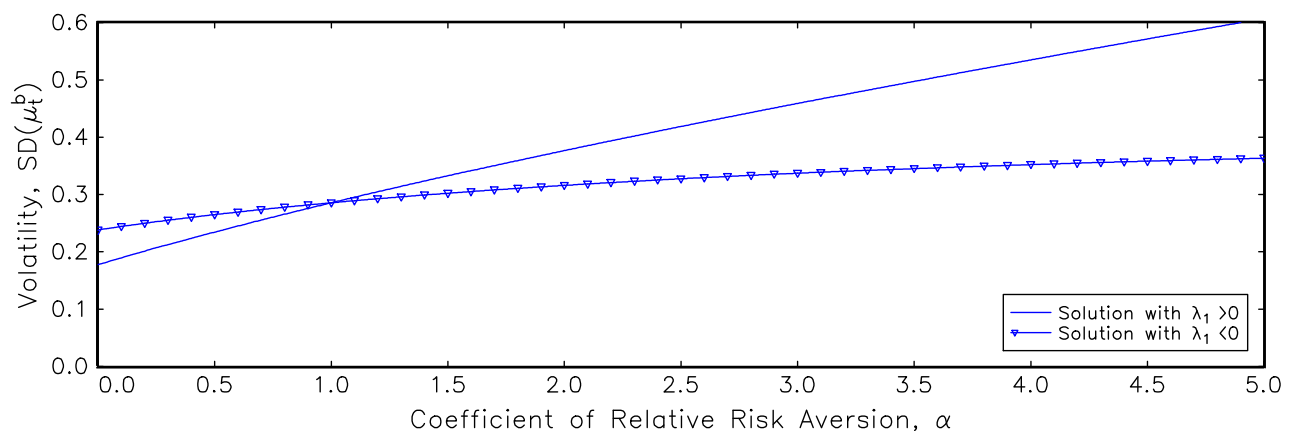

Figure 4: Properties of two rational bubble solutions without drift.

price-dividend ratio

$$
y_{t}^{\mathrm{b}}=y_{t-1}^{\mathrm{b}} \exp \left[\left(\lambda_{1}-\theta\right)\left(x_{t}-\bar{x}\right)-\rho \lambda_{1}\left(x_{t-1}-\bar{x}\right)\right], \quad y_{0}^{\mathrm{b}}>0,
$$

where I have made the substitution $\lambda_{2}=-\left(\rho \lambda_{1}+\theta\right)$. The above equation shows that $y_{t}^{\mathrm{b}}$ follows a geometric random walk without drift. Starting from an arbitrarily small positive value of $y_{0}^{\mathrm{b}}$, the bubble component will expand and contract in an irregular fashion, with the trajectory of $y_{t}=y_{t}^{\mathrm{f}}+y_{t}^{\mathrm{b}}$ always returning to the vicinity of $y_{t}^{\mathrm{f}}$. As with all intrinsic bubbles, the stochastic properties of the bubble innovations depend exclusively on fundamentals. Equation (28) implies

$$
\begin{aligned}
E\left(\mu_{t}^{\mathrm{b}}\right) & =0 \\
\operatorname{Var}\left(\mu_{t}^{\mathrm{b}}\right) & =\left[\left(\lambda_{1}-\theta\right)^{2}+\left(\rho \lambda_{1}\right)^{2}-2 \rho^{2} \lambda_{1}\left(\lambda_{1}-\theta\right)\right] \frac{\sigma_{\varepsilon}^{2}}{1-\rho^{2}} .
\end{aligned}
$$

Figure 4 a shows the values of $\lambda_{1}$ that satisfy the no-drift equilibrium condition $\left(\lambda_{1}\right)^{2} \sigma_{\varepsilon}^{2} / 2+$ $\theta \bar{x}+\log (\beta)=0$. The equilibrium values are given by the intersections with the horizontal zero line. For each value of the risk coefficient $\alpha$, there are two values of $\lambda_{1}$ that yield a 
driftless bubble such that $E\left(\mu_{t}^{\mathrm{b}}\right)=0$. Figure $4 \mathrm{~b}$ plots the volatility of the bubble drift rate as a function of the risk coefficient. The bubble solution with $\lambda_{1}>0$ has lower volatility for $\alpha<1$, but higher volatility for $\alpha>1$. Both solutions exhibit more volatility as risk aversion increases.

Proposition 5 shows that the bubble solutions presented in Propositions 2, 3, and 4 are special cases along a continuum of rational bubble equilibria.

Proposition 5. There exists a continuum of intrinsic rational bubbles of the form

$$
z_{t}^{\mathrm{b}}=z_{t-1}^{\mathrm{b}} \exp \left[\lambda_{0}+\lambda_{1}\left(x_{t}-\bar{x}\right)+\lambda_{2}\left(x_{t-1}-\bar{x}\right)\right], \quad z_{0}^{\mathrm{b}}>0
$$

where $\lambda_{0}, \lambda_{1}$, and $\lambda_{2}$ are any three constants that satisfy the following two equilibrium conditions

$$
\begin{aligned}
& \frac{1}{2}\left(\lambda_{1}\right)^{2} \sigma_{\varepsilon}^{2}+\theta \bar{x}+\log (\beta)+\lambda_{0}=0, \\
& \lambda_{2}=-\left(\rho \lambda_{1}+\theta\right) .
\end{aligned}
$$

Proof: See appendix.

The proof of Proposition 5 shows that the results are the same, regardless of whether the agent is assumed to make use of the contemporaneous or lagged realization of $z_{t}^{\mathrm{b}}$ when forming the rational expectation $E_{t} z_{t+1}^{\mathrm{b}}$. A continuum of solutions exists because the agent's forecast rule for $E_{t} z_{t+1}^{\mathrm{b}}$ is overparameterized, relative to what is needed to satisfy equation (21). The equilibrium condition that relates the drift parameter $\lambda_{0}$ to the volatility parameter $\lambda_{1}$ formalizes the trade-off between the mean and the volatility of the bubble drift rate. To recover the Froot-Obstfeld bubble in Proposition 2, we impose $\lambda_{0}=\left(\lambda_{1}+\lambda_{2}\right) \bar{x}$. To recover the bubble with drift in Proposition 3 , we impose $\lambda_{2}=0$. To recover the driftless bubble in Proposition 4 , we impose $\lambda_{0}=0$. Other valid solutions can be obtained by imposing $\lambda_{1}=0$ or say, by imposing the arbitrary restriction $\lambda_{1}=\lambda_{2}$. The volatility of the bubble drift rate $\operatorname{Var}\left(\mu_{t}^{\mathrm{b}}\right)$ can be minimized by imposing $\lambda_{1}=\theta$. A so-called "time bubble" occurs in the special case when $\rho=0$ and $\lambda_{1}=\theta$, thus yielding $\operatorname{Var}\left(\mu_{t}^{\mathrm{b}}\right)=0$.

\section{A Near-Rational Asset Pricing Solution}

All of the rational bubble solutions derived in the previous section imply non-stationary behavior of the price-dividend ratio. The solutions require the representative agent to construct both a fundamental forecast $E_{t} z_{t+1}^{\mathrm{f}}$ and bubble forecast $E_{t} z_{t+1}^{\mathrm{b}}$ each period. Furthermore, the model is silent on how the agent would choose among a continuum of rational bubble forecasts.

As an alternative to a rational bubble, this section presents a near-rational asset pricing solution that: (1) requires the agent to construct only a single forecast each period, (2) involves a parsimonious forecast rule that is parameterized by matching the moments of the observable data, and (3) yields a stationary, but highly persistent nonlinear law of motion for the pricedividend ratio. 
I assume that the agent's perceived law of motion (PLM) for the total forecast variable $z_{t}=z_{t}^{\mathrm{f}}+z_{t}^{\mathrm{b}}$ is given by

$$
z_{t}=z_{t-1} \exp \left[b\left(x_{t}-\bar{x}\right)\right], \quad z_{0}>0
$$

which is a geometric random walk without drift. The functional form of the PLM bears similarity to both the approximate fundamental solution in Proposition 1 and the driftless rational bubble solution in Proposition 4. For an agent with limited computational resources, equation (31) is an attractive candidate PLM because it allows for nonstationary bubble behavior and involves only a single parameter $b$ that can be readily estimated from observable data. The estimated version of the PLM can be used to construct a single forecast that predicts the movement of the total asset price (fundamental plus bubble).

In constructing the subjective forecast $\widehat{E}_{t} z_{t+1}$, I assume that the agent cannot make use of the contemporaneous realization $z_{t}$, but rather uses the lagged realization $z_{t-1}$. Use of the lagged realization ensures that the forecast is "operational." Since equation (8) implies that $z_{t}$ depends on the agent's own forecast, it is not clear how the agent could make use of $z_{t}$ when constructing the forecast in real-time. A lagged information assumption is commonly used in adaptive learning models because it avoids simultaneity in the determination of the actual and expected values of the forecast variable.

As in a rational solution, I assume the representative agent is endowed with the knowledge of the stochastic process for dividends. The underlying assumption is that enough time has elapsed for the agent to correctly identify the stochastic process from observable data. With the above assumptions, the PLM can be iterated ahead two periods to compute the following subjective expectation:

$$
\widehat{E}_{t} z_{t+1}=z_{t-1} \exp \left[b(1+\rho)\left(x_{t}-\bar{x}\right)+\frac{1}{2} b^{2} \sigma_{\varepsilon}^{2}\right],
$$

where the exponential term can be interpreted as a time-varying extrapolation factor applied to the most recent observation. ${ }^{10}$ For comparison, the rational forecast implied by Propositions 1 and 4 is given by

$$
\begin{aligned}
E_{t} z_{t+1}= & \underbrace{\exp \left[a_{0}+a_{1} \rho\left(x_{t}-\bar{x}\right)+\frac{1}{2}\left(a_{1}\right)^{2} \sigma_{\varepsilon}^{2}\right]}_{E_{t} z_{t+1}^{\mathrm{f}}} \\
& +\underbrace{z_{t-1}^{\mathrm{b}} \exp \left\{\left[\lambda_{1}(1+\rho)+\lambda_{2}\right]\left(x_{t}-\bar{x}\right)+\lambda_{2}\left(x_{t-1}-\bar{x}\right)+\frac{1}{2}\left(\lambda_{1}\right)^{2} \sigma_{\varepsilon}^{2}\right\}}_{E_{t} z_{t+1}^{\mathrm{b}}} .
\end{aligned}
$$

where, for symmetry, I have assumed that $E_{t} z_{t+1}^{\mathrm{b}}$ makes use of the lagged realization $z_{t-1}^{\mathrm{b}}$. Not counting $\bar{x}, \rho$, and $\sigma_{\varepsilon}$ which are presumed known, the rational forecast rule (33) involves four separate parameters $\left(a_{0}, a_{1}, \lambda_{1}\right.$, and $\left.\lambda_{2}\right)$, as opposed to the subjective forecast rule (32)

\footnotetext{
${ }^{10}$ Lansing $(2006)$ considers a model in which the agent's PLM is given by $z_{t}=z_{t-1} \exp \left(v_{t}\right)$, where $v_{t} \sim$ $N\left(0, \sigma_{v}^{2}\right)$ is a perceived exogenous shock that is unrelated to dividend/consumption growth. In this case, the extrapolation factor is constant rather than time-varying.
} 
which involves only a single parameter $b$. An agent with limited computational resources might be inclined to adopt the more parsimonious forecast rule (32).

Substituting the subjective forecast rule (32) into equation (8) in place of a rational forecast yields the following actual law of motion (ALM):

$$
z_{t}=\beta \exp \left(\theta x_{t}\right)\left\{z_{t-1} \exp \left[b(1+\rho)\left(x_{t}-\bar{x}\right)+\frac{1}{2} b^{2} \sigma_{\varepsilon}^{2}\right]+1\right\},
$$

which is nonlinear and autoregressive. The ALM for the price-dividend ratio can be recovered

from the above expression by making use of the equilibrium relationship $y_{t}=\widehat{E}_{t} z_{t+1}$, where $\widehat{E}_{t} z_{t+1}$ is given by equation (32) with $z_{t-1}=\beta \exp \left(\theta x_{t-1}\right)\left(y_{t-1}+1\right)$. This procedure yields

$$
y_{t}=\left(y_{t-1}+1\right) \beta \exp \left[b(1+\rho)\left(x_{t}-\bar{x}\right)+\theta x_{t-1}+\frac{1}{2} b^{2} \sigma_{\varepsilon}^{2}\right],
$$

which is also nonlinear and autoregressive. The stationarity properties of price-dividend ratio depend on the value of the forecast parameter $b$. For comparison, equation (31) can be converted into the following PLM for the price-dividend ratio

$$
y_{t}=\left(y_{t-1}+1\right) \exp \left[(b-\theta)\left(x_{t}-\bar{x}\right)+\theta\left(x_{t-1}-\bar{x}\right)\right]-1,
$$

which is similar, but not identical, to the form of the ALM (35).

\subsection{Restricted Perceptions Equilibrium}

This section derives a "restricted perceptions equilibrium" (RPE) in which the forecast parameter $b$ is pinned down using the moments of observable data. Since the agent's PLM (31) implies that $z_{t}$ is nonstationary, it is natural to assume that the agent's forecast rule is parameterized to match the covariance of $\Delta \log \left(z_{t}\right)$ and $x_{t}$.

The PLM implies that $b$ is given by

$$
b=\frac{\operatorname{Cov}\left[\Delta \log \left(z_{t}\right), x_{t}\right]}{\operatorname{Var}\left(x_{t}\right)}
$$

where both $\operatorname{Cov}\left[\Delta \log \left(z_{t}\right), x_{t}\right]$ and $\operatorname{Var}\left(x_{t}\right)$ can be computed from observable data. An analytical expression for the observable covariance can be derived using the following loglinear approximation to the nonlinear ALM (34):

$$
z_{t} \simeq z_{t-1}^{k} \bar{z}^{1-k} \exp \left[m\left(x_{t}-\bar{x}\right)\right]
$$

where $k$ and $m$ are Taylor-series coefficients and $\bar{z}=\exp \left(E\left[\log \left(z_{t}\right)\right]\right)$ is the non-stochastic steady state level of $z_{t}$. Straightforward computations yield the following expressions for the parameters of the approximate law of motion

$$
\begin{aligned}
k & =\beta \exp \left[\theta \bar{x}+\frac{1}{2} b^{2} \sigma_{\varepsilon}^{2}\right] \\
m & =\theta+b(1+\rho) \beta \exp \left[\theta \bar{x}+\frac{1}{2} b^{2} \sigma_{\varepsilon}^{2}\right] \\
\bar{z} & =\frac{\beta \exp (\theta \bar{x})}{1-\beta \exp \left[\theta \bar{x}+\frac{1}{2} b^{2} \sigma_{\varepsilon}^{2}\right]},
\end{aligned}
$$


which all depend in a nonlinear way on the subjective forecast parameter $b$. The approximate law of motion of $\Delta \log \left(z_{t}\right)$ can be computed directly from equation (38), which in turn yields the following expression for the relevant covariance

$$
\operatorname{Cov}\left[\Delta \log \left(z_{t}\right), x_{t}\right]=\left[\frac{(1-\rho) m}{1-\rho k}\right] \operatorname{Var}\left(x_{t}\right),
$$

which is nonlinear in $b$ via the expressions for $k$ and $m$. Details of the derivation are contained in the appendix. Equations (37) and (42) can be combined to form the following definition of equilibrium.

Definition 1. A near-rational "restricted perceptions equilibrium" is defined as a perceived law of motion (31), an approximate actual law of motion (38), and a subjective forecast rule parameter $b$, such that the equilibrium value $b$ is given by the fixed point of the nonlinear map

$$
b=T(b) \equiv \frac{(1-\rho) m(b)}{1-\rho k(b)},
$$

where $k(b)$ and $m(b)$ are parameters of the approximate actual law of motion that depend on $b$, as given by equations (39) and (40), provided that $k(b) \leq 1$.

In equilibrium, we require $k(b) \leq 1$ so that $\Delta \log \left(z_{t}\right)$ remains stationary, thereby allowing $\operatorname{Cov}\left[\Delta \log \left(z_{t}\right), x_{t}\right]$ to be computed from observable data. If $k(b)<1$, then $\log \left(z_{t}\right)$ is stationary.

The approximate ALM (38) can be used to derive the following analytical expressions for the unconditional moments of the asset pricing variables

$$
\begin{aligned}
E\left[\log \left(y_{t}\right)\right] & =\log \left(\frac{k}{1-k}\right), \quad k<1, \\
E\left[\log \left(R_{t+1}\right)\right] & =-\log (\beta)+\alpha \bar{x}-\frac{1}{2} b^{2} \sigma_{\varepsilon}^{2},
\end{aligned}
$$

where $k$ is given by equation (39). The expression for $E\left[\log \left(R_{t+1}\right)\right]$ has the same form as the fundamental mean return $E\left[\log \left(R_{t+1}^{\mathrm{f}}\right)\right]$ given by equation (18), except that $\left(a_{1}\right)^{2}$ is replaced here by $b^{2}$. At the baseline calibration, we have $a_{1}=-0.86$ an $b=-5.03$, so the near-rational mean return is below that of the fundamental solution. This result can be traced to a small amount of optimism in the near-rational forecast rule rule (32), as demonstrated in the next section. Optimism has an effect on the mean return that is similar to increasing patience about future payoffs via a higher value for the discount factor $\beta$. The appendix contains analytical expressions for the unconditional variances $\operatorname{Var}\left[\log \left(y_{t}\right)\right]$ and $\operatorname{Var}\left[\log \left(R_{t+1}\right)\right]$.

\subsection{Numerical Solution for the Equilibrium}

The complexity of the nonlinear map $b=T(b)$ necessitates a numerical solution for the equilibrium. Parameters are set to the same values used in Figure 1a.

Figure 5 a plots $T(b)$ over the range $-30 \leq b \leq 30$. There are three fixed points. Only the middle fixed point yields a stationary equilibrium such that $k<1$, as shown in Figure $5 \mathrm{~b}$. At 
5a: Solving for the Near-Rational Equilibrium

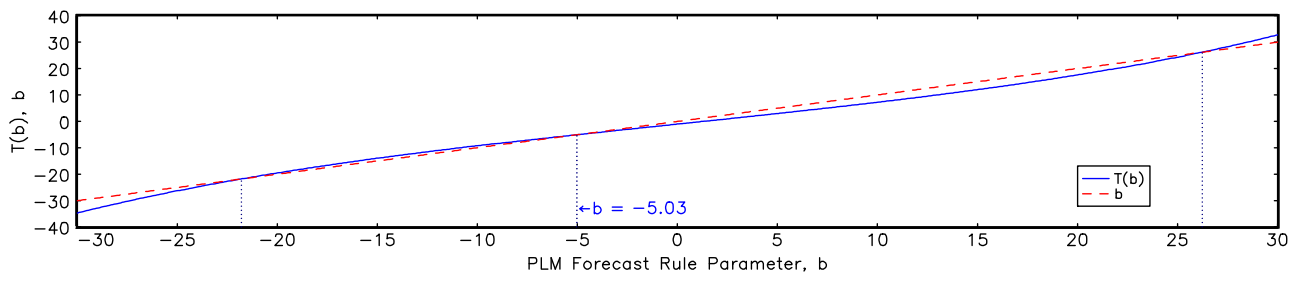

5a: Stability of the Near-Rational Equilibrium

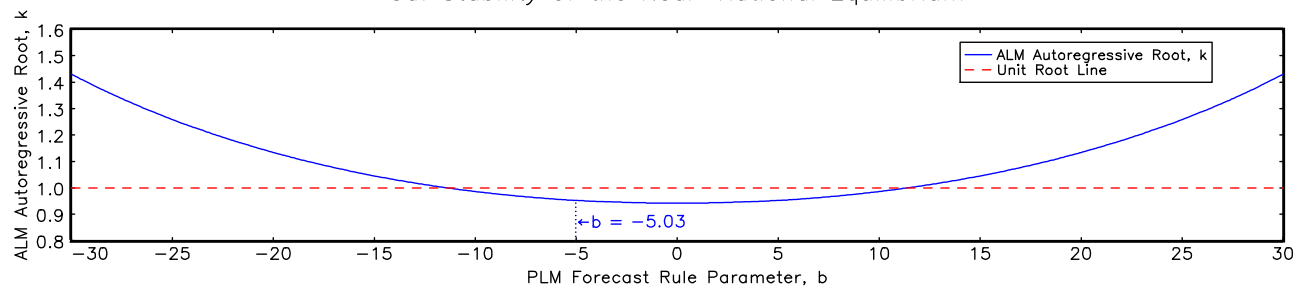

5c: Autocorrelation of Percentage Forecast Errors

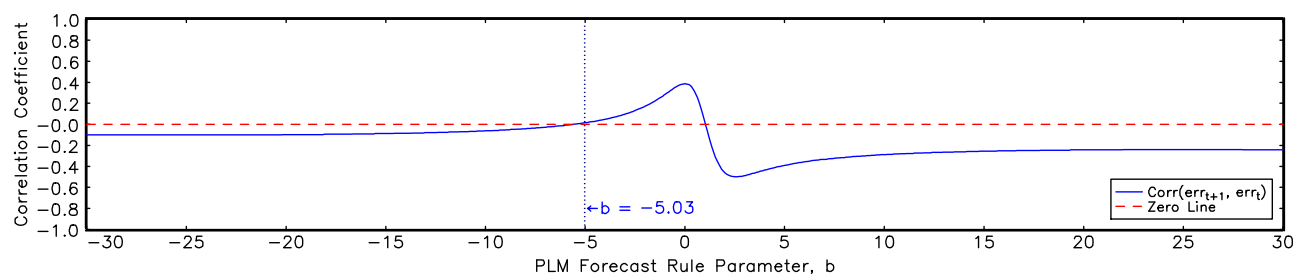

Figure 5: Numerical solution and properties of the near-rational equilibrium.

the middle fixed point, we have $b=-5.03$, and $k=0.95$. The ALM response coefficient on $\left(x_{t}-\bar{x}\right)$ is $m=-4.99$. When $k=1$ and $m=b$, the approximate ALM (38) coincides exactly with the PLM (31). At the middle fixed point, we have $k \simeq 1$ and $m \simeq b$, such that the RPE can be described as "near-rational."

Making use of the approximate ALM (38) and the subjective forecast rule (32), the percentage forecast error observed by the agent is given by

$$
\begin{aligned}
e r r_{t+1} & =\log \left(\frac{z_{t+1}}{\widehat{E}_{t} z_{t+1}}\right), \\
& =\log \left\{\frac{z_{t}^{k} \bar{z}^{1-k} \exp \left[m\left(x_{t+1}-\bar{x}\right)\right]}{z_{t-1} \exp \left[b(1+\rho)\left(x_{t}-\bar{x}\right)+\frac{1}{2} b^{2} \sigma_{\varepsilon}^{2}\right]}\right\},
\end{aligned}
$$

where $k$ and $m$ are given by equations (39) and (40). Recalling that $\bar{z}=\exp \left(E\left[\log \left(z_{t}\right)\right]\right)$, the above equation implies

$$
E\left(e r r_{t+1}\right)=-\frac{1}{2} b^{2} \sigma_{\varepsilon}^{2} .
$$

At the equilibrium value $b=-5.03$, with $\sigma_{\varepsilon}=0.030$, we have $E\left(e r r_{t+1}\right)=-0.012$, indicating a small amount of optimism in the agent's subjective forecast. Optimism about future payoffs makes the agent more willing to defer current consumption and increase saving, thereby driving 
6a: Convergence to Near-Rational Equilibrium

PLM Forecast Rule Parameter

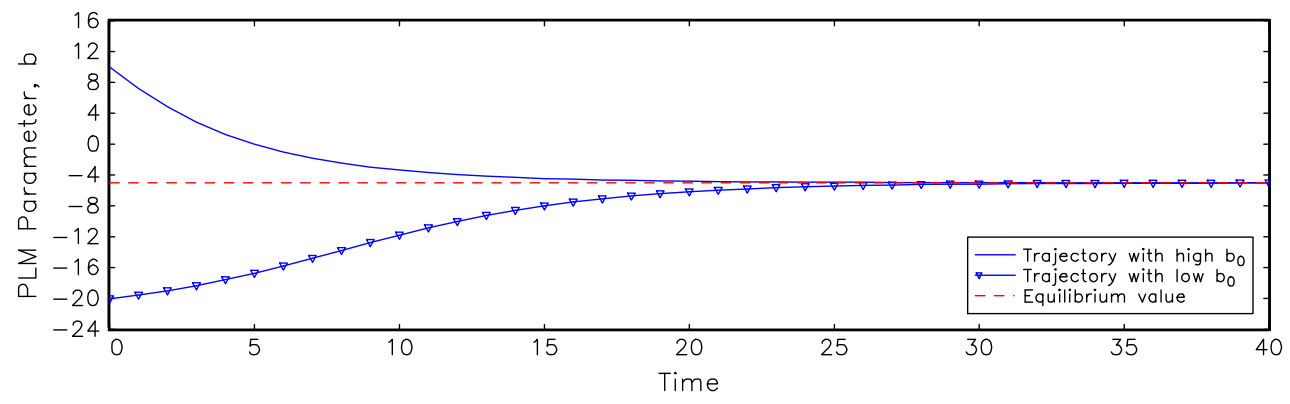

6b: Convergence to Near-Rational Equilibrium

ALM Autoregressive Root

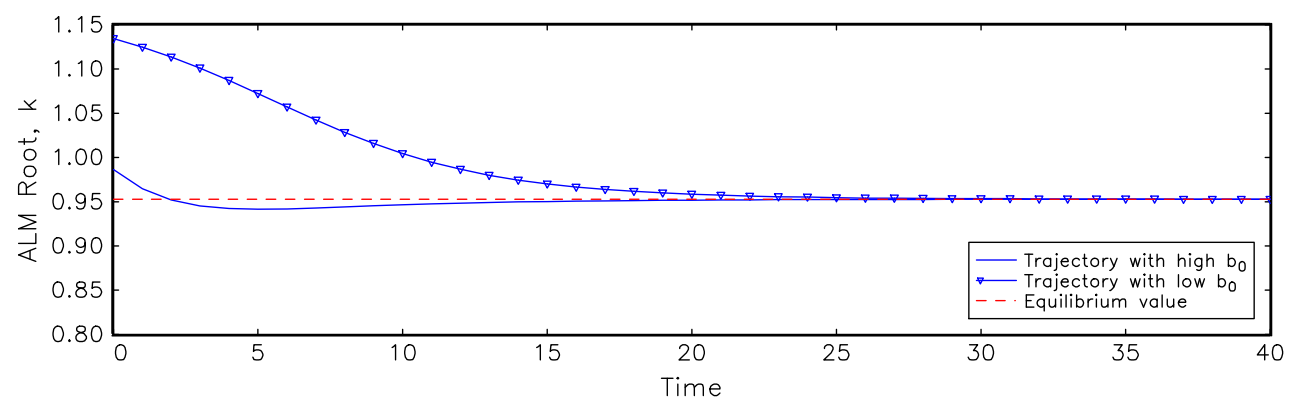

Figure 6: Iterating the nonlinear map $b_{t+1}=T\left(b_{t}\right)$ for different starting values $b_{0}$.

up the share price and reducing the mean return. Conversely, pessimism about future payoffs serves to increase the mean return, as demonstrated by Abel (2002).

Equation (45) can be used to derive an analytical expression for the autocorrelation of percentage forecast errors $\operatorname{Corr}\left(\operatorname{err}_{t+1}, e r r_{t}\right)$, as outlined in the appendix. Figure 5c plots $\operatorname{Corr}\left(\operatorname{err}_{t+1}, e r r_{t}\right)$. At the equilibrium value $b=-5.03$, the autocorrelation is 0.014 . The near-zero autocorrelation of the forecast errors makes it difficult for the agent to detect a misspecification of the subjective forecast rule (32).

Figure 6 a plots the convergence to the near-rational equilibrium by iterating the nonlinear map as follows: $b_{t+1}=T\left(b_{t}\right)$. The map converges for starting values $b_{0}$ which are either above or below the equilibrium value $b=-5.03$. Convergence requires only 20 to 25 iterations. Figure $6 \mathrm{~b}$ plots the corresponding trajectories for the ALM autoregressive root $k$, as computed from equation (39). The exercise demonstrates that the near-rational equilibrium is stable under a form of real-time learning. The equilibrium can be described as "iteratively E-stable" in the terminology of Evans and Honkapohja (2001, p. 373). 


\section{Model Simulations}

Table 1 presents unconditional moments of asset pricing variables computed from a long-run simulation of the model. The table also reports the corresponding statistics from U.S. data over the period 1871 to $2003 .^{11}$ The fundamental solution is simulated using the expressions in Proposition 1. The expressions in Propositions 2 and 4 are used to simulate the rational bubble solutions, which are superimposed on top of the fundamental solution. ${ }^{12}$ For the rational bubble solutions, the initial level of the bubble component $y_{0}^{\mathrm{b}}$ is set equal to 1 percent of the steady-state fundamental price-dividend ratio. For the fundamental and near-rational solutions, the initial condition is the corresponding steady-state price-dividend ratio.

The top section of Table 1 shows that the near-rational solution does an excellent job of matching the unconditional moments of the U.S. price-dividend ratio. The U.S. ratio exhibits high volatility, positive skewness, excess kurtosis, and strong positive serial correlation. In contrast, the fundamental solution delivers low volatility, near-zero skewness, no excess kurtosis, and weak negative serial correlation which is inherited directly from the consumption growth process with $\rho=-0.166$. The rational bubble solutions imply that the price-dividend ratio is non-stationary, so the corresponding moments do not exist.

The middle section of Table 1 compares unconditional moments for the drift rate of the price-dividend ratio - a stationary variable for all model solutions. As noted earlier in the discussion of Figure 3, the mean drift rate in U.S. data is 0.01 versus a drift rate of 0.06 for the Froot-Obstfeld solution. The near-rational solution provides a good match with the higher moments of the U.S. drift rate.

The last section of Table 1 compares unconditional moments for the net equity return. The mean return for the near-rational solution is about 1 percentage point below that of the fundamental solution (7.35 percent versus 8.30 percent). As noted earlier, this result can be traced to the small amount of optimism in the near-rational forecast. The returns generated by the near-rational solution exhibit positive serial correlation, albeit slightly stronger than those observed in U.S. data.

Figures $7 \mathrm{a}$ through $7 \mathrm{~h}$ plot simulated data for the different solutions of the model. The left-side panels show the price dividend ratio $y_{t}=y_{t}^{\mathrm{f}}+y_{t}^{\mathrm{b}}$, while the right-side panels show the net equity return $R_{t}-1$. The explosive price-dividend ratio in the Froot-Obstfeld solution with $\lambda_{1}>0$ can be seen in Figure 7a, which employs a logarithmic scale. The corresponding equity return remains stationary and exhibits time-varying volatility (Figure $7 \mathrm{~b}$ ). The two driftless rational bubble solutions exhibit irregularly-spaced episodes of expanding and contracting bubbles (Figures 7c and 7e). Return volatility increases dramatically during these episodes (Figures $7 d$ and $7 f$ ).

\footnotetext{
${ }^{11}$ The price-dividend ratio in year $t$ is defined as the value of the S\&P 500 stock index at the beginning of year $t+1$, divided by the accumulated dividend over year $t$.

12 "Driftless Bubble 1" refers to the solution in Proposition 4 with $\lambda_{1}>0$, while "Driftless Bubble 2" refers to the solution with $\lambda_{1}<0$.
} 
Table 1. Unconditional Moments

\begin{tabular}{|c|c|c|c|c|c|c|}
\hline \multirow[b]{2}{*}{ Statistic } & \multirow[b]{2}{*}{$\begin{array}{c}\text { U.S. Data } \\
1871-2003\end{array}$} & \multicolumn{5}{|c|}{ Model Simulations } \\
\hline & & $\begin{array}{l}\text { Funda- } \\
\text { mental }\end{array}$ & $\begin{array}{c}\text { Froot- } \\
\text { Obstfeld }\end{array}$ & $\begin{array}{c}\text { Driftless } \\
\text { Bubble } 1\end{array}$ & $\begin{array}{c}\text { Driftless } \\
\text { Bubble } 2 \\
\end{array}$ & $\begin{array}{c}\text { Near- } \\
\text { Rational }\end{array}$ \\
\hline$y_{t}=p_{t} / d_{t}$ & & & - & - & - & \\
\hline Mean & 25.7 & 16.3 & - & - & - & 26.0 \\
\hline Std. Dev. & 13.0 & 0.07 & - & - & - & 15.0 \\
\hline Skew. & 2.55 & -0.01 & - & - & - & 2.52 \\
\hline Kurt. & 10.6 & 3.00 & - & - & - & 12.8 \\
\hline Corr. Lag 1 & 0.93 & -0.17 & - & - & - & 0.97 \\
\hline \multicolumn{7}{|l|}{$\log \left(y_{t} / y_{t-1}\right)$} \\
\hline Mean & 0.01 & 0.00 & 0.06 & 0.00 & 0.00 & 0.00 \\
\hline Std. Dev. & 0.20 & 0.01 & 0.08 & 0.06 & 0.27 & 0.13 \\
\hline Skew. & -0.06 & 0.02 & -0.02 & 0.26 & 0.04 & 0.03 \\
\hline Kurt. & 3.02 & 3.00 & 3.00 & 86.3 & 4.11 & 3.00 \\
\hline Corr. Lag 1 & -0.09 & -0.58 & -0.07 & -0.11 & 0.02 & 0.04 \\
\hline \multicolumn{7}{|l|}{$R_{t}-1$} \\
\hline Mean & $8.30 \%$ & $8.25 \%$ & $8.70 \%$ & $8.23 \%$ & $7.01 \%$ & $7.35 \%$ \\
\hline Std. Dev & $17.8 \%$ & $3.95 \%$ & $12.6 \%$ & $8.20 \%$ & $26.6 \%$ & $10.8 \%$ \\
\hline Skew. & -0.02 & 0.09 & 0.33 & 4.40 & 1.01 & 0.33 \\
\hline Kurt. & 2.78 & 3.02 & 3.21 & 100.1 & 5.88 & 3.19 \\
\hline Corr. Lag 1 & 0.03 & -0.29 & -0.10 & -0.15 & 0.02 & 0.15 \\
\hline
\end{tabular}

Note: Model statistics are based on a 10,000 period simulation after dropping 500 periods.

Parameter values: $\bar{x}=0.019, \sigma_{\varepsilon}=0.030, \rho=-0.166, \alpha=2$, and $\beta=0.96$.

Table 2. 20-Year Rolling Volatility of Returns

\begin{tabular}{ccccccc}
\hline \hline & & \multicolumn{5}{c}{ Model Simulations } \\
\cline { 3 - 7 } Std. Dev. & U.S. Data & $\begin{array}{c}\text { Funda- } \\
\text { mental }\end{array}$ & $\begin{array}{c}\text { Froot- } \\
\text { Obstfeld }\end{array}$ & $\begin{array}{c}\text { Driftless } \\
\text { Bubble 1 }\end{array}$ & $\begin{array}{c}\text { Driftless } \\
\text { Bubble 2 }\end{array}$ & $\begin{array}{c}\text { Near- } \\
\text { Rational }\end{array}$ \\
\hline & & & & & \\
Min 20-Yr & $18.5 \%$ & $1.66 \%$ & $3.10 \%$ & $1.66 \%$ & $1.16 \%$ & $5.22 \%$ \\
Max 20-Yr & $27.9 \%$ & $7.21 \%$ & $23.5 \%$ & $75.6 \%$ & $52.2 \%$ & $16.5 \%$ \\
Full Sample. & $17.8 \%$ & $3.95 \%$ & $12.6 \%$ & $8.20 \%$ & $26.6 \%$ & $10.8 \%$ \\
\hline
\end{tabular}

Notes: Model statistics are based on a 10,000 period simulation after dropping 500 periods.

Parameter values: $\bar{x}=0.019, \sigma_{\varepsilon}=0.030, \rho=-0.166, \alpha=2$, and $\beta=0.96$. 
7a: Froot-Obstfeld Rational Bubble $\left(\lambda_{1}>0\right)$

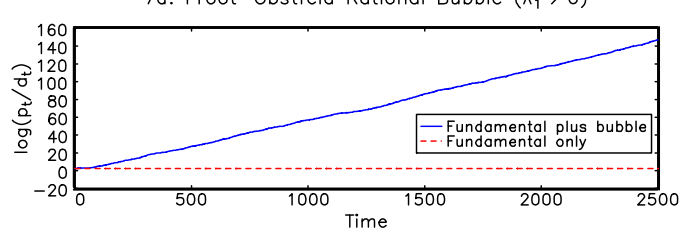

7c: Driftless Rational Bubble $\left(\lambda_{1}>0\right)$

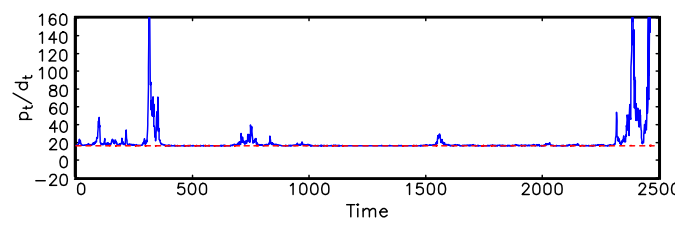

7e: Driftless Rational Bubble $\left(\lambda_{1}<0\right)$

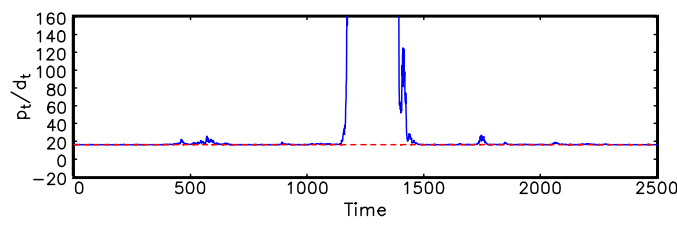

7g: Near-Rational Solution

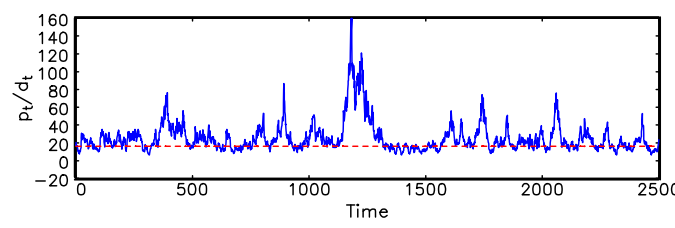

7b: Froot-Obstfeld Rational Bubble $\left(\lambda_{1}>0\right)$

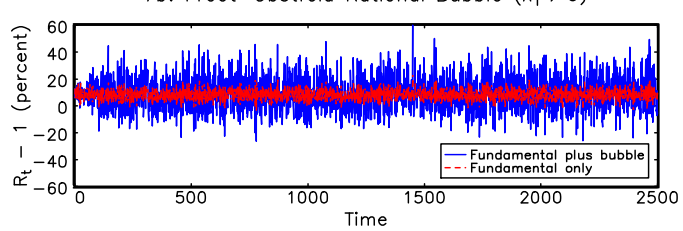

7d: Driftless Rational Bubble $\left(\lambda_{1}>0\right)$

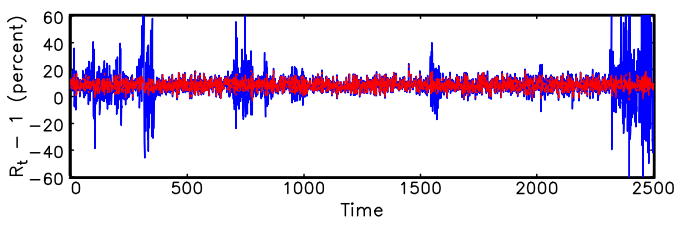

7f: Driftless Rational Bubble $\left(\lambda_{1}<0\right)$

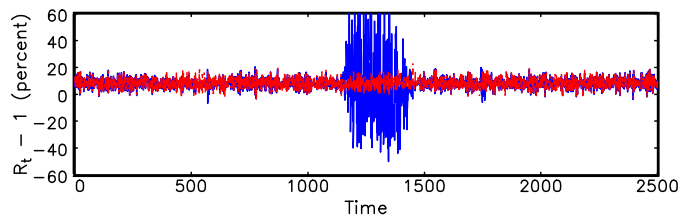

7h: Near-Rational Solution

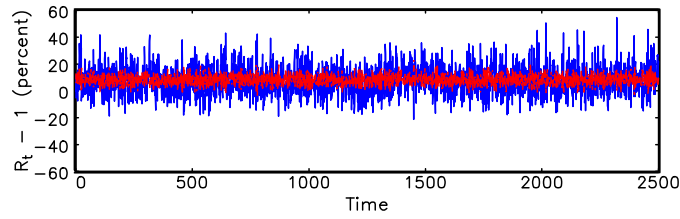

Figure 7: Left panels: price-dividend ratio. Right panels: net equity return.

Bohl and Siklos (2004) and Coakley and Fuertes (2006) fit nonlinear time series models to U.S. stock market valuation ratios over the period 1871 to 2001 . Both studies find evidence that valuation ratios drift upwards into bubble territory during bull markets, but these persistent departures from fundamentals are eventually eliminated via downward adjustments during bear markets. Recent empirical tests for nonstationarity of the U.S. price-dividend ratio are inconclusive. Engsted (2006) finds support for a rational bubble in U.S. data. In contrast, a study by Koustas and Serletis (2005) rejects the rational bubble hypothesis in favor of a mean-reverting behavior for the U.S. price-dividend ratio.

The near-rational solution generates pronounced low-frequency swings in the price-dividend ratio that occasionally dip below the fundamental value (Figure $7 \mathrm{~g}$ ). In contrast, rational bubble solutions require the price-dividend ratio to always remain above the fundamental. ${ }^{13}$ The timing of expanding and contracting bubble episodes in Figure $7 \mathrm{~g}$ is somewhat similar to that generated by the driftless rational bubble solution with $\lambda_{1}<0$ plotted in Figure 7e. Both solutions involve a negative sign applied to the fundamental term $\left(x_{t}-\bar{x}\right)$ in the corresponding law of motion.

\footnotetext{
${ }^{13}$ Weil (1990) notes that a positive rational bubble can cause the equilibrium asset price to dip below the ex ante fundamental value if there is sufficient feedback from the bubble to either dividends or the discount rate.
} 


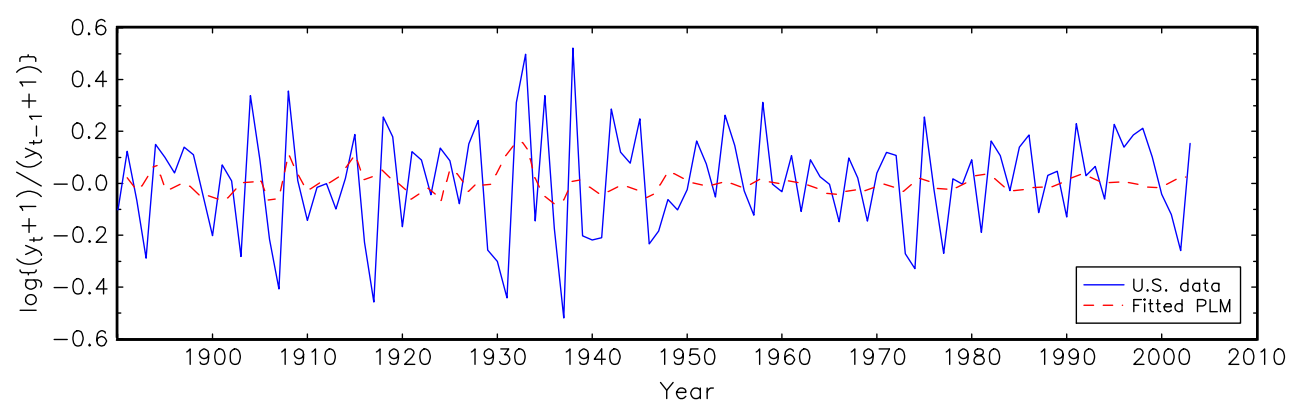

8b: U.S. Price-Dividend Ratio, 1891-2003

Data versus Fitted ALM

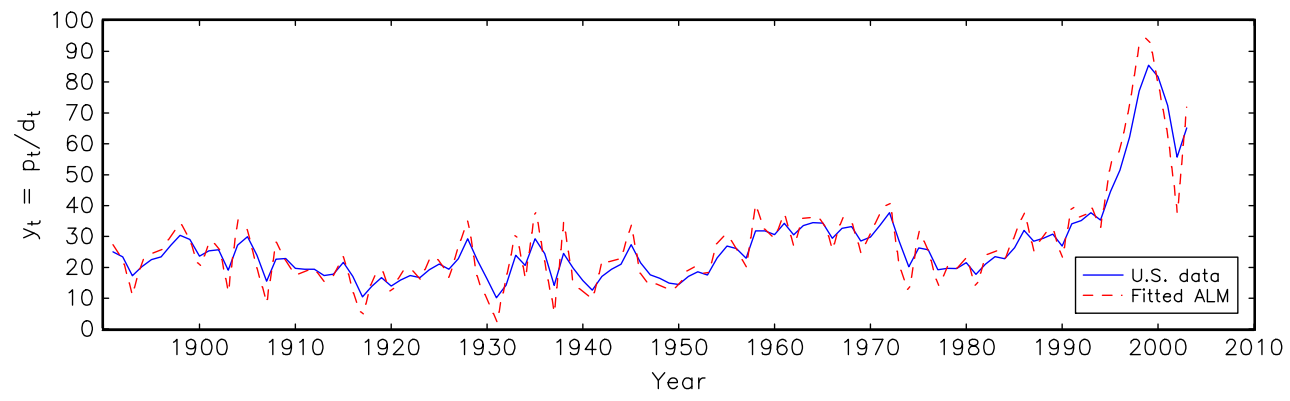

Figure 8: Fitting the perceived and actual laws of motion to long-run U.S. data.

The nonlinear nature of the ALM (35) gives rise to time-varying return volatility (Figure $7 \mathrm{~h})$. Table 2 provides a quantitative comparison of the return volatilities in U.S. data and the various model solutions. From 1871 to 2003, the 20-year rolling standard deviation of U.S. returns varies from a minimum of $12.5 \%$ to a maximum of $27.9 \%$. The Froot-Obstfeld solution provides the best match with the data, followed by the near-rational solution.

Figure 8a shows the results of regressing the PLM (36) in first-difference form on U.S. data for the price-dividend ratio and per capita consumption growth. The regression attempts to replicate the manner in which the representative agent would estimate the parameter $b$ using the covariance (37). For the regression, I impose $\alpha=2$ and $\bar{x}=0.019$. The regression yields $b=-2.11$ (s.e. $=0.58$ ), which is reasonably close to the theoretical value of $b=-5.03$ implied by the restricted perceptions equilibrium. Figure $8 \mathrm{~b}$ shows the results of regressing the ALM (35) in level form on U.S. data. I impose $\beta=0.96, \alpha=2, \bar{x}=0.019, \sigma_{\varepsilon}=0.030$, and $\rho=-0.166$. This regression yields $b=-0.753$ (s.e. $=0.89$ ), which has the same sign as the theoretical value, but is not statistically different from zero. The excellent fit shown in Figure $8 \mathrm{~b}$ is a consequence of the highly persistent nature of the ALM (35) for any value of $b$. From the model's perspective, the substantial run-up in U.S. price dividend ratio at the end of the sample can be interpreted as a long swing that results when random shocks impinge upon a 
highly-persistent law of motion. ${ }^{14}$

Table 3 provides a quantitative comparison of forecast errors between the fundamental and near-rational solutions. As expected, the fundamental solution delivers a lower root mean squared percentage error. However, the near-rational forecast errors are close to white noise at all lags - giving no indication to the agent that the subjective forecast rule (32) is misspecified.

Table 3: Comparison of Percentage Forecast Errors

\begin{tabular}{ccc}
\hline \hline & \multicolumn{2}{c}{ Model Simulations } \\
Statistic & Fundamental & Near-Rational \\
\hline$E\left(e r r_{t+1}\right)$ & 0.00 & -0.01 \\
$\sqrt{E\left(e r r_{t+1}^{2}\right)}$ & 0.03 & 0.16 \\
$\operatorname{Corr}\left(\operatorname{err}_{t+1}, e r r_{t}\right)$ & -0.01 & 0.01 \\
$\operatorname{Corr}\left(\operatorname{err}_{t+1}, \operatorname{err}_{t-1}\right)$ & -0.01 & -0.03 \\
$\operatorname{Corr}\left(\operatorname{err}_{t+1}, \operatorname{err}_{t-2}\right)$ & -0.01 & -0.02 \\
\hline
\end{tabular}

Notes: Model statistics are based on a 10,000 period simulation after dropping 500 periods.

Parameter values: $\bar{x}=0.019, \sigma_{\varepsilon}=0.030, \rho=-0.166, \alpha=2$, and $\beta=0.96$.

\section{Concluding Remarks}

There are many examples throughout history where asset prices appear to have experienced sustained run-ups above fundamental values. Departures from fundamentals typically prove to be temporary. It is a challenge for a asset pricing theory to explain such phenomena within a framework of efficient capital markets. Rational bubbles are an attractive modeling device because the framework allows asset prices to exceed fundamentals while imposing a no-arbitrage condition over short time horizons. In a rational bubble solution, an asset is valued not for its cash flows, but rather for its potential for capital gain - a description that seems to fit the prevailing psychology during historical bubble episodes.

This paper demonstrated the existence of a continuum of intrinsic rational bubble solutions that involve an equilibrium trade-off between the mean and volatility of the bubble drift rate. When the mean drift rate of the bubble is zero by construction, the short-term prospects for capital gain derive solely from the higher volatility of the bubble component. A driftless rational bubble exhibits irregularly-spaced expansions and collapses that are wholly endogenous. Starting from an arbitrarily small degree of overvaluation, the asset price will always return to the vicinity of the fundamental solution.

Strictly speaking, rational bubbles are actually "near-rational" because the transversality condition is not satisfied. In a world where agents' computational resources are limited, small movements away from a rational bubble solution seem quite plausible. The near-rational asset

\footnotetext{
${ }^{14}$ Boswijk, et al. (2007) interpret the run-up in the U.S. price-dividend ratio as an increase in the prevalence of trend-chasing agents versus fundamentalists. In their model, the shift in the composition of agents is a long swing driven by a series of random shocks.
} 
pricing solution developed in this paper is based on a parsimonious and versatile forecast rulea geometric random walk without drift. When the forecast rule is parameterized to match the moments of observable data, the resulting forecast errors are close to white noise. The near-rational solution does a good job of matching many quantitative features of U.S. stock market data and allows the equity price to occasionally dip below the fundamental price. 


\section{A Appendix: Proofs and Derivations}

\section{A.1 Proof of Proposition 1 (Approximate Fundamental Solution)}

Iterating ahead the conjectured law of motion for $z_{t}^{\mathrm{f}}$ and taking the conditional expectation yields

$$
E_{t} z_{t+1}^{\mathrm{f}}=\exp \left[a_{0}+\rho a_{1}\left(x_{t}-\bar{x}\right)+\frac{1}{2}\left(a_{1}\right)^{2} \sigma_{\varepsilon}^{2}\right] .
$$

Substituting the above expression into the first order condition (8) and then taking logarithms yields

$$
\begin{aligned}
\log \left(z_{t}^{\mathrm{f}}\right)=F\left(x_{t}\right)= & \log (\beta)+\theta x_{t} \\
& +\log \left\{\exp \left[a_{0}+\rho a_{1}\left(x_{t}-\bar{x}\right)+\frac{1}{2}\left(a_{1}\right)^{2} \sigma_{\varepsilon}^{2}\right]+1\right\} \\
\simeq & a_{0}+a_{1}\left(x_{t}-\bar{x}\right)
\end{aligned}
$$

where $a_{0}$ and $a_{1}$ are the Taylor-series coefficients for an approximation of $F\left(x_{t}\right)$ around the non-stochastic steady state $\bar{x}$. The Taylor-series coefficients are given by

$$
\begin{aligned}
& F(\bar{x})=a_{0}=\log (\beta)+\theta \bar{x}+\log \left\{\exp \left[a_{0}+\frac{1}{2}\left(a_{1}\right)^{2} \sigma_{\varepsilon}^{2}\right]+1\right\} \\
& F^{\prime}(\bar{x})=a_{1}=\theta+\frac{\rho a_{1} \exp \left[a_{0}+\frac{1}{2}\left(a_{1}\right)^{2} \sigma_{\varepsilon}^{2}\right]}{\exp \left[a_{0}+\frac{1}{2}\left(a_{1}\right)^{2} \sigma_{\varepsilon}^{2}\right]+1} .
\end{aligned}
$$

Solving equation (A.3) for $a_{0}$ yields

$$
a_{0}=\log \left\{\frac{\beta \exp (\theta \bar{x})}{1-\beta \exp \left[\theta \bar{x}+\frac{1}{2}\left(a_{1}\right)^{2} \sigma_{\varepsilon}^{2}\right]}\right\},
$$

which can be substituted into equation (A.4) to yield the following nonlinear equation that determines $a_{1}$ :

$$
a_{1}=\theta+\rho a_{1} \beta \exp \left[\theta \bar{x}+\frac{1}{2}\left(a_{1}\right)^{2} \sigma_{\varepsilon}^{2}\right] .
$$

Solving equation (A.6) for $a_{1}$ yields the nonlinear equation shown in Proposition 1. There are

two solutions, but only one solution satisfies the condition $\beta \exp \left[\theta \bar{x}+\frac{1}{2}\left(a_{1}\right)^{2} \sigma_{\varepsilon}^{2}\right]<1$ such that $\exp \left(a_{0}\right)=\exp \left[E \log \left(z_{t}^{\mathrm{f}}\right)\right]>0$.

\section{A.2 Asset Pricing Moments (Fundamental Solution)}

This section briefly outlines the derivation of equations (16) through (19).

Equation (16) follows directly from equation (15) by taking the unconditional expectation of $\log \left(y_{t}^{\mathrm{f}}\right)$. We have

$$
\log \left(y_{t}^{\mathrm{f}}\right)-E\left[\log \left(y_{t}^{\mathrm{f}}\right)\right]=a_{1} \rho_{1}\left(x_{t}-\bar{x}\right)
$$


which implies $\operatorname{Var}\left[\log \left(y_{t}^{\mathrm{f}}\right)\right]=\left(a_{1}\right)^{2} \rho^{2} \operatorname{Var}\left(x_{t}\right)$, as given by equation (17).

The fundamental equity return can be written as

$$
\begin{aligned}
R_{t+1}^{\mathrm{f}} & =\left(\frac{y_{t+1}^{\mathrm{f}}+1}{y_{t}^{\mathrm{f}}}\right) \exp \left(x_{t+1}\right), \\
& =\left(\frac{z_{t+1}^{\mathrm{f}}}{\beta E_{t} z_{t+1}^{\mathrm{f}}}\right) \exp \left(\alpha x_{t+1}\right),
\end{aligned}
$$

where I have eliminated $y_{t}^{\mathrm{f}}$ using the equilibrium relationship $y_{t}^{\mathrm{f}}=E_{t} z_{t+1}^{\mathrm{f}}$ and eliminated $y_{t+1}^{\mathrm{f}}$ using the definitional relationship $y_{t+1}^{\mathrm{f}}+1=\beta^{-1} \exp \left(-\theta x_{t+1}\right) z_{t+1}^{\mathrm{f}}$. Substituting in $z_{t+1}^{\mathrm{f}}=$ $\exp \left[a_{0}+a_{1}\left(x_{t}-\bar{x}\right)\right]$ from Proposition 1 and $E_{t} z_{t+1}^{\mathrm{f}}$ from equation (15) and then taking the unconditional expectation of $\log \left(R_{t+1}^{\mathrm{f}}\right)$ yields equation (18). We have

$$
\log \left(R_{t+1}^{\mathrm{f}}\right)-E\left[\log \left(R_{t+1}^{\mathrm{f}}\right)\right]=\alpha\left(x_{t+1}-\bar{x}\right)+a_{1} \varepsilon_{t+1}
$$

which in turns implies

$$
\operatorname{Var}\left[\log \left(R_{t+1}^{\mathrm{f}}\right)\right]=\alpha^{2} \operatorname{Var}\left(x_{t}\right)+\left(a_{1}\right)^{2} \sigma_{\varepsilon}^{2}+2 \alpha a_{1} \operatorname{Cov}\left(x_{t}, \varepsilon_{t}\right),
$$

as given by equation (19).

\section{A.3 Proof of Proposition 5 (Continuum of Intrinsic Rational Bubbles)}

The proof of Proposition 5 covers Propositions 2, 3, and 4 since these are just special cases of Proposition 5.

First consider the case where the agent can make use of the contemporaneous realization $z_{t}^{\mathrm{b}}$ when forming the rational expectation $E_{t} z_{t+1}^{\mathrm{b}}$. Iterating ahead the conjectured law of motion for $z_{t}^{\mathrm{b}}$ by one period and then taking the conditional expectation yields

$$
E_{t} z_{t+1}^{\mathrm{b}}=z_{t}^{\mathrm{b}} \exp \left[\lambda_{0}+\left(\rho \lambda_{1}+\lambda_{2}\right)\left(x_{t}-\bar{x}\right)+\frac{1}{2}\left(\lambda_{1}\right)^{2} \sigma_{\varepsilon}^{2}\right] .
$$

Substituting the above expression into the no-arbitrage condition (21) and then taking logarithms yields

$$
0=\log (\beta)+\theta x_{t}+\lambda_{0}+\left(\rho \lambda_{1}+\lambda_{2}\right)\left(x_{t}-\bar{x}\right)+\frac{1}{2}\left(\lambda_{1}\right)^{2} \sigma_{\varepsilon}^{2}
$$

where $\log \left(z_{t}^{\mathrm{b}}\right)$ has been cancelled from both sides. For equation (A.8) to hold, the constant terms and the coefficients on $x_{t}$ must separately sum to zero. Equilibrium therefore requires

$$
\begin{array}{r}
\frac{1}{2}\left(\lambda_{1}\right)^{2} \sigma_{\varepsilon}^{2}-\underbrace{\left(\rho \lambda_{1}+\lambda_{2}\right)}_{-\theta} \bar{x}+\log (\beta)+\lambda_{0}=0, \\
\theta+\rho \lambda_{1}+\lambda_{2}=0,
\end{array}
$$

which represent a system of two equations in three unknown constants $\lambda_{0}, \lambda_{1}$, and $\lambda_{2}$. The solutions to equations (A.13) and (A.14) define a continuum of intrinsic rational bubble equilibria. Now consider the case where the agent can only make use of the lagged realization $z_{t-1}^{\mathrm{b}}$ 
when forming $E_{t} z_{t+1}^{\mathrm{b}}$. Iterating ahead the conjectured law of motion for $z_{t}^{\mathrm{b}}$ by one period and then substituting out $z_{t}^{\mathrm{b}}$ using the same law of motion yields

$$
z_{t+1}^{\mathrm{b}}=z_{t-1}^{\mathrm{b}} \exp \left\{2 \lambda_{0}+\left[\lambda_{1}(1+\rho)+\lambda_{2}\right]\left(x_{t}-\bar{x}\right)+\lambda_{2}\left(x_{t-1}-\bar{x}\right)+\lambda_{1} \varepsilon_{t+1}\right\},
$$

where I have eliminated $\left(x_{t+1}-\bar{x}\right)$ using the law of motion for dividend growth (35). Taking the conditional expectation of the above expression yields

$$
E_{t} z_{t+1}^{\mathrm{b}}=z_{t-1}^{\mathrm{b}} \exp \left\{2 \lambda_{0}+\left[\lambda_{1}(1+\rho)+\lambda_{2}\right]\left(x_{t}-\bar{x}\right)+\lambda_{2}\left(x_{t-1}-\bar{x}\right)+\frac{1}{2}\left(\lambda_{1}\right)^{2} \sigma_{\varepsilon}^{2}\right\} .
$$

Substituting the above expression into the no-arbitrage condition (21) and then taking logarithms yields

$$
\begin{aligned}
\log \left(z_{t}^{\mathrm{b}}\right)=\log \left(z_{t-1}^{\mathrm{b}}\right)+\log (\beta) & +\theta x_{t}+2 \lambda_{0}+\left[\lambda_{1}(1+\rho)+\lambda_{2}\right]\left(x_{t}-\bar{x}\right) \\
& +\lambda_{2}\left(x_{t-1}-\bar{x}\right)+\frac{1}{2}\left(\lambda_{1}\right)^{2} \sigma_{\varepsilon}^{2},
\end{aligned}
$$

which can be compared to the following expression for the logarithm of the conjectured law of motion:

$$
\log \left(z_{t}^{\mathrm{b}}\right)=\log \left(z_{t-1}^{\mathrm{b}}\right)+\lambda_{0}+\lambda_{1}\left(x_{t}-\bar{x}\right)+\lambda_{2}\left(x_{t-1}-\bar{x}\right) .
$$

Equation (A.17) will coincide exactly with equation (A.18) when the following equilibriums conditions are satisfied

$$
\begin{aligned}
\log (\beta)+2 \lambda_{0}-\left[\lambda_{1}(1+\rho)+2 \lambda_{2}\right] \bar{x}+\frac{1}{2}\left(\lambda_{1}\right)^{2} \sigma_{\varepsilon}^{2} & =\lambda_{0}-\left(\lambda_{1}+\lambda_{2}\right) \bar{x} \\
\theta+\lambda_{1}(1+\rho)+\lambda_{2} & =\lambda_{1}
\end{aligned}
$$

which are isomorphic to the equilibrium conditions (A.13) and (A.14).

\section{A.4 Asset Pricing Moments (Near-Rational Solution)}

Starting from the approximate ALM (38), the law of motion of $\Delta \log \left(z_{t}\right)$ can be written as:

$$
\Delta \widehat{z}_{t}=(k-1)\left[\widehat{z}_{t-1}-E\left(\widehat{z}_{t}\right)\right]+m\left(x_{t}-\bar{x}\right),
$$

where $\widehat{z}_{t} \equiv \log \left(z_{t}\right)$. The above equation implies:

$$
\operatorname{Cov}\left(\Delta \widehat{z}_{t}, x_{t}\right)=(k-1) \operatorname{Cov}\left(\widehat{z}_{t-1}, x_{t}\right)+m \operatorname{Var}\left(x_{t}\right) .
$$

From (38), we have $\operatorname{Cov}\left(\widehat{z}_{t-1}, x_{t}\right)=[\rho m /(1-\rho k)] \operatorname{Var}\left(x_{t}\right)$, which can be substituted into (A.22) to yield equation (42) in the text.

The ALM for the price-dividend ratio, equation (35), can be rewritten as follows:

$$
\begin{aligned}
y_{t} & =\left(y_{t-1}+1\right) \beta \exp \left[b(1+\rho)\left(x_{t}-\bar{x}\right)+\theta x_{t-1}+\frac{1}{2} b^{2} \sigma_{\varepsilon}^{2}\right], \\
& =\left(y_{t-1}+1\right) k \exp \left[\left(\frac{m-\theta}{k}\right)\left(x_{t}-\bar{x}\right)+\theta\left(x_{t-1}-\bar{x}\right)\right],
\end{aligned}
$$


where I have eliminated $b$ and $b^{2}$ using the expressions for the Taylor series coefficients $k$ and $m$, as given by equations (39) and (40). Taking logarithms of the above expression yields

$$
\begin{aligned}
\widehat{y}_{t} & =\log \left[\exp \left(\widehat{y}_{t-1}\right)+1\right]+\log (k)+\left(\frac{m-\theta}{k}\right)\left(x_{t}-\bar{x}\right)+\theta\left(x_{t-1}-\bar{x}\right), \\
& \simeq n_{0}+n_{1}\left[\widehat{y}_{t-1}-E\left(\widehat{y}_{t}\right)\right]+\left(\frac{m-\theta}{k}\right)\left(x_{t}-\bar{x}\right)+\theta\left(x_{t-1}-\bar{x}\right),
\end{aligned}
$$

where $\widehat{y}_{t} \equiv \log \left(y_{t}\right)$, and $n_{0}$ and $n_{1}$ are Taylor series coefficients. Straightforward computations yield $n_{0}=\log [k /(1-k)]$ and $n_{1}=k$. The unconditional expectation of the above expression yields $E\left(\widehat{y}_{t}\right)=n_{0}$, as given by equation (43).

Using equation (A.24), the unconditional variance can be computed as follows:

$$
\begin{aligned}
\operatorname{Var}\left(\widehat{y}_{t}\right)= & E\left\{\left[\widehat{y}_{t}-E\left(\widehat{y}_{t}\right)\right]^{2}\right\} \\
= & \left(\frac{1}{1-k^{2}}\right)\left[\left(\frac{m-\theta}{k}\right)^{2}+\theta^{2}+2\left(\frac{m-\theta}{k}\right) \theta \rho\right] \operatorname{Var}\left(x_{t}\right), \\
& +\left[\frac{2(m-\theta) \rho+2 \theta k}{1-k^{2}}\right] \operatorname{Cov}\left(\widehat{y}_{t}, x_{t}\right),
\end{aligned}
$$

where $\operatorname{Cov}\left(\widehat{y}_{t}, x_{t}\right)$ can also be computed from equation (A.24).

The equity return is given by

$$
\begin{aligned}
R_{t+1} & =\left(\frac{z_{t+1}}{\beta \widehat{E}_{t} z_{t+1}}\right) \exp \left(\alpha x_{t+1}\right) \\
& =\frac{z_{t}^{k} \bar{z}^{1-k} \exp \left[m\left(x_{t+1}-\bar{x}\right)+\alpha x_{t+1}\right]}{\beta z_{t-1} \exp \left[b(1+\rho)\left(x_{t}-\bar{x}\right)+\frac{1}{2} b^{2} \sigma_{\varepsilon}^{2}\right]},
\end{aligned}
$$

where I have substituted in the approximate ALM (38) and the subjective expectation (32). Taking the unconditional expectation of $\widehat{R}_{t+1} \equiv \log \left(R_{t+1}\right)$ yields equation (44). From (A.26), we have

$$
\begin{aligned}
\widehat{R}_{t+1}-E\left(\widehat{R}_{t+1}\right)= & \underbrace{k\left[\widehat{z}_{t}-E\left(\widehat{z}_{t}\right)\right]}_{k^{2}\left[\widehat{z}_{t-1}-E\left(\widehat{z}_{t}\right)\right]+k m\left(x_{t}-\bar{x}\right)}-\left[\widehat{z}_{t-1}-E\left(\widehat{z}_{t}\right)\right] \\
& +(m+\alpha)\left(x_{t+1}-\bar{x}\right)-b(1+\rho)\left(x_{t}-\bar{x}\right),
\end{aligned}
$$

which can be used to compute an analytical expression for $\operatorname{Var}\left(\widehat{R}_{t+1}\right)$.

From equation (45), the law of motion for the percentage forecast error is given by

$$
\begin{aligned}
e r r_{t+1}-E\left(e r r_{t+1}\right)= & \left(1-k^{2}\right)\left[\widehat{z}_{t-1}-E\left(\widehat{z}_{t}\right)\right] \\
& +[k m+m \rho-b(1+\rho)]\left(x_{t}-\bar{x}\right)+m \varepsilon_{t+1},
\end{aligned}
$$

where I have eliminated $\left[\widehat{z}_{t}-E\left(\widehat{z}_{t}\right)\right]$ using the approximate $\operatorname{ALM}(38)$. Equation (A.28) is used to compute $\operatorname{Corr}\left(\operatorname{err}_{t+1}, \operatorname{err}_{t}\right)=\operatorname{Cov}\left(e r r_{t+1}, e r r_{t}\right) / \operatorname{Var}\left(\operatorname{err}_{t+1}\right)$, as plotted in Figure 5. 


\section{References}

[1] Abel, A.B. 2002 An exploration of the effects of pessimism and doubt on asset returns, Journal of Economic Dynamics and Control 26, 1075-1092.

[2] Abreu, D. and M.K. Brunnermeier 2003 Bubbles and crashes. Econometrica 71, 173-204.

[3] Barberis, N., A. Shleifer, and R.W. Vishny 1998 A model of investor sentiment, Journal of Financial Economics 49, 307-343.

[4] Barsky, R.B. and J.B. De Long 1993 Why does the stock market fluctuate? Quarterly Journal of Economics 107, 291-311.

[5] Bohl, M.T. and P.L. Siklos 2004 The present value model of U.S. stock prices redux: A new testing strategy and some evidence, Quarterly Review of Economics and Finance 44, 208-223.

[6] Blanchard, O.J. 1979 Speculative bubbles, crashes, and rational expectations, Economics Letters 3, 387-389.

[7] Blanchard, O.J. and M.W. Watson (1982) Bubbles, rational expectations and financial markets. In P. Wachtel (ed.), Crises in the Economic and Financial Structure, pp. 295315. Lexington MA: Lexington Books.

[8] Boswijk, H.P., C.H. Hommes, and S. Manzan 2007 Behavioral heterogeneity in stock prices, Journal of Economic Dynamics and Control, 31, 1938-1970.

[9] Branch, W.A. and G.W. Evans 2006 Asset return dynamics and learning, Working paper.

[10] Brock, W.A. and C.H. Hommes 1998 Heterogenous beliefs and routes to chaos in a simple asset pricing model. Journal of Economic Dynamics and Control 22, 1235-1274.

[11] Burnside, C. 1998 Solving asset pricing models with Gaussian shocks, Journal of Economic Dynamics and Control 22, 329-340.

[12] Calin, O.L., Y. Chen, T.F. Cosimano, and A.A. Himonas 2005 Solving asset pricing models when the price-dividend ratio function is analytic, Econometrica 73, 961-982.

[13] Cecchetti, S.G., P.-S. Lam, and N.C. Mark 2000 Asset pricing with distorted beliefs: Are equity returns too good to be true? American Economic Review 90, 787-805.

[14] Coakley, J. and A. Fuertes 2006 Valuation ratios and price deviations from fundamentals, Journal of Banking and Finance, 30, 2325-2346.

[15] Collard, F. and M. Juillard 2001 Accuracy of stochastic perturbation methods: The case of asset pricing models, Journal of Economic Dynamics and Control 25, 979-999.

[16] Delong, J.B., A. Shleifer, L.H. Summers, and R.J. Waldmann 1990 Noise trader risk in financial markets, Journal of Political Economy 98, 703-738.

[17] Diba, B.T. and H.I. Grossman 1988 The theory of rational bubbles in stock prices, Economic Journal 98, 746-754.

[18] Driffill, J. and M. Sola 1998 Intrinsic bubbles and regime-switching, Journal of Monetary Economics 42, 357-373.

[19] Engsted T. 2006 Explosive bubbles in the cointegrated VAR model, Finance Research Letters 3, 154-162. 
[20] Evans, G.W. 1991 Pitfalls in testing for explosive bubbles in asset prices, American Economic Review 81, 922-930.

[21] Froot, K. and M. Obstfeld 1991 Intrinsic bubbles: The case of stock prices, American Economic Review 81, 1189-1214.

[22] Fukata, Y. 1998 A simple discrete approximation of continuous-time bubbles, Journal of Economic Dynamics and Control 22, 937-954.

[23] Gürkaynak, R.S. 2007 Econometric tests of asset price bubbles: Taking stock, Journal of Economic Surveys, forthcoming.

[24] Hall, R.E. 2001 Struggling to understand the stock market, American Economic Review Papers and Proceedings 91, 1-11.

[25] Hunter, W.C., G.G. Kaufman, and M. Pomerleano, (Eds.) 2003 Asset Price Bubbles, The Implications for Monetary, Regulatory, and International Policies. Cambridge, MA: MIT Press.

[26] Ikeda, S. and A. Shibata 1992 Fundamentals-dependent bubbles in stock prices, Journal of Monetary Economics 30, 143-168.

[27] Koustas, Z. and A. Serletis 2005 Rational bubbles or peristent deviations from market fundamentals? Journal of Banking and Finance 29, 2523-2539.

[28] Lansing, K.J. 2006 Lock-in of extrapolative expectations in an asset pricing model, Macroeconomic Dynamics 10, 317-348.

[29] LeRoy, S.F. 2004 Rational exuberance, Journal of Economic Literature 152, 783-804.

[30] LeRoy, S.F. and R.D. Porter 1981 The present-value relation: Tests based on implied variance bounds, Econometrica 49, 555-577.

[31] Lucas, R.E. 1978 Asset prices in an exchange economy, Econometrica 46, 1429-1445.

[32] Santos, M.S. and M. Woodford 1997 Rational Asset Pricing Bubbles, Econometrica 65, $19-57$

[33] Scheinkman, J.A. and W. Xiong 2003 Overconfidence and Speculative bubbles, Journal of Political Economy 111, 1183-1219.

[34] Shiller, R.J. 1981 Do stock prices move too much to be justified by subsequent changes in dividends? American Economic Review 71, 421-436.

[35] Shiller, R.J. 2003 From efficient markets theory to behavioral finance, Journal of Economic Perspectives 17 (Winter), 83-104.

[36] Timmerman, A. 1996 Excess volatility and predictability of stock prices in autoregressive dividend models with learning, Review of Economic Studies, 63, 523-557.

[37] Van Norden, S. and H. Schaller 1999 Speculative behavior, regime switching, and stock market crashes. In P. Rothman (ed.), Nonlinear Time Series Analysis of Economic and Financial Data, pp. 321-356. Boston: Kluwer.

[38] Weil, P. 1990 On the possibility of price decreasing bubbles, Econometrica 58, 1467-1474. 